ISSN 1112-9867

Available online at $\quad$ http://www.jfas.info

\title{
CONSERVATION LAW OF PLANTS' ENERGY VALUE DEPENDENCE OF PLANTS' NEED IN NUTRIENTS ON BIOCHEMICAL COMPOSITION
}

\author{
A. V. Reichardt*, S. V. Lebedev \\ Kuibysheva str., Zavolzhsk, Ivanovo oblast, Russia, 155410
}

Published online: 08 August 2017

\begin{abstract}
The plants differences in biochemical composition are analyzed, and the conservation law of energy value in plants is obtained. The link between the need for the nutrients and the plants biochemical composition is examined, Liebig's law is specified.
\end{abstract}

Keywords: plant's biochemical composition, biochemistry, energy value in plants, plants' nutrition.

\section{INTRODUCTION}

"Global population growth and the increase in the number of starving and malnourished people, changes in dietary habits, and thus the demand increase for food require the significant intensification of the agricultural output. Therefore, the majority of the civilized countries of the world pays special attention to the development of the high-yield farming, the soil fertility recovery and the provision of the high-quality food for the population. Mineral and organic plants fertilizers are one of the boosting factor in farming and plant growing intensification" (Nechaeva and Bykova, 2014)

The increase of crops yield capacity is one of the key challenges faced by a mankind. Efficient use of mineral fertilizers is the most crucial factor for the agriculture intensification. It has widely been known that every crop requires its own individual amount of nutrients.

Author Correspondence, e-mail: author@gmail.com

doi: http://dx.doi.org/10.4314/jfas.v9i2s.847 
There is a rationale to identify the underlying determinants for the nutrients necessary for the appropriate growth of plants provided the other factors (humidity, temperature, light, etc.) are adequate for the specified yield capacity of the crops. If we refer to the principle from Liebig's law of the minimum and Shelford's law of tolerance which states that with any yield capacity the factors are within the tolerance range, i.e. not higher and not lower the critical levels, then the element content in the plants given further matches the optimal level for the specified yield capacity.

Generally, all annual plants contain the same substances: carbohydrates, protein, fats and water, but they are different in the substances' proportions. For a person, the energy value of a plant is of importance, and this value, in its turn, is characterized by the amount of protein, fats and carbohydrates. It is obvious that the plant nutrition depends on its chemical composition, and the solution for the problem is interdisciplinary - biochemistry and agrochemistry.

\section{Research}

First, it is necessary to gather the information and to categorize all plants by their biochemical composition. It is not possible to find the data on the biochemical composition of the plants, that is why certain work was carried out to find the information about the biochemical composition of fruits and the plants' need in nutrients.

As the paper describes a wide variety of crops, the fruits are the edible part of a plant (corn, beans, roots, tuberous roots, etc.)

Latter calculations show that the average need of soybean in nitrogen leads to the negative result for protein in fruit-free plant weight, that is why for the further calculations, soybean need in nitrogen is supposed to equal the maximum need of $326 \mathrm{gr}$ per $5 \mathrm{~kg}$ of yield by the source (Adamenko and Kostyushko, n.d.), which is 62.5 gr per $1 \mathrm{~kg}$ of yield.

In the initial data the carbohydrate content is supposed to be the person-consumed carbohydrates, therefore for the further calculations it is necessary to know the overall amount of carbohydrates including the undigested fiber.

Fiber share of digested carbohydrate weight for all plants is on average $25 \%$. Keeping it in mind the overall amount of carbohydrates is taken to be 1.25 time more than the amount of digested carbohydrates.

To identify the link between the biochemical composition of a plant and the nutrient consumption, it is important to know both the biochemical composition of fruits and the biochemical composition of all fruit-free plant weight. 
All nitrogen consumed by a plant is spent on protein and nonprotein compounds formation. Average content of nitrogen in protein and nonprotein compounds is 16\% (Smirnov and Muravin, 1977). With the need of a plant in nitrogen, one can accurately calculate the overall protein content.

* We take the maximum need of soybean in nitrogen as the average values of soybean need in nitrogen give the negative value of protein in fruit-free plant weight.

It may be assumed that the biochemical composition of fruit-free plant weight and biochemical composition of herbaceous plants can be similar. Let us consider the biochemical composition of feedstuff herbage (Table 14) and check the stability of biochemical composition, i.e. the preservation of the proportions between the protein, fats and carbohydrates with no regard to the type of feedstuff herbage.

Biochemical composition of feedstuff herbage is stable, but, first, let us check the biochemical composition of fruits without jumping to conclusion (Table 15).

Biochemical composition of fruits is also stable - the proportions between protein, fats and carbohydrates do not change regardless of fruit type (Figure 2). Let us compare the compositions in Table 16.

The content of protein and fats in herbage is a bit higher than in the fruits. This is likely to be explained by the seeds in feedstuff herbage. With this, for our further calculations of overall weight of a plant we use the biochemical composition of fruits (Figure 2).

Energy value (EV) of food is the amount of energy released from food in a person's body during the digestion provided the food is completely digested, and EV numerically equals the sum of energy values of protein, fats and carbohydrates in the food.

Energy value (EV) of a plant is the overall amount of energy accumulated in protein, fats and carbohydrates in the whole vegetative system of a plant, including all fibers. And the energy accumulated in fiber weight quantitatively equals the energy value of the same weight of digested carbohydrates as the same amount of energy is released when the same weight of carbohydrates and fibers is burnt.

From the source (Tablitsa kaloriynosti..., n.d.) the energy value of protein is $4.1 \mathrm{kcal} / \mathrm{gr}$, that of fats is $9.3 \mathrm{kcal} / \mathrm{gr}$, that of carbohydrates is $4.1 \mathrm{kcal} / \mathrm{gr}$. The energy value $(\mathrm{EV})$ of fats is 2.268 times higher than carbohydrate and protein EVs.

Photosynthesis is the only source of carbohydrates for all living organisms. Part of the carbohydrates from the photosynthesis under the impact from the enzymes is spent to form protein and fats. 
To simplify the information understanding, let us introduce the concept of energy value equivalent (EVE) which equals the weight of all carbohydrates formed under photosynthesis during vegetation and is calculated by a formula:

$\mathrm{EVE}=\mathrm{P}+2,268 * \mathrm{~F}+\mathrm{C}$, where $\mathrm{P}, \mathrm{F}, \mathrm{C}$ are the protein, fats and carbohydrate weight respectively, and 2.268 is the coefficient of carbohydrate energy conversion into energy of fats.

With EVE we can find the energy value of plants by a formula:

$\mathrm{EV}=\mathrm{EVE}$ (energy value equivalent) $* 4.1 \mathrm{kcal}$

Let us graphically present the weight of protein, fats and carbohydrates of all plants in their dependence on EVE and add an interpolation line of dependence of protein, fats and carbohydrate weight with EVE lower than 400 (Figure 3).

The graph (Figure 3) shows that the wheat with EVE higher than 400 is also within this regularity. It can clearly been seen that such crops as colza and soybean significantly deviate from the interpolation line. We can see that colza has increased amount of proteins and fats but its carbohydrate content is greatly lower than the interpolation line illustrating the carbohydrate dependence on the energy value. The same is true for soybean with the increased protein content.

Let us find the energy value equivalent of deviations (Table 19).

EVE deviations tend to zero, that is why we may say that biochemical composition in colza and soybean is redistributed, and carbohydrate energy quantitatively transforms into the protein and fat energy.

With due regard to said above, it is necessary to introduce the concepts of the relative weights of protein $(\mathrm{Pg})$, fats $(\mathrm{Fg})$ and carbohydrates $(\mathrm{Cg})$ which are directly proportionate to the energy value equivalent, are on the interpolation lines (Figure 3) and are calculated by a formula:

$\operatorname{Pg}(\mathrm{EVE})=0.1018 * \mathrm{EVE}$

$\mathrm{Fg}(\mathrm{EVE})=0.0132 * \mathrm{EVE}$

$\mathrm{Cg}(\mathrm{EVE})=0.8683 * \mathrm{EVE}$

Let us also introduce the concept of relative dry weight of plants $(\mathrm{Wg})$, which is the sum of relative weights of protein $(\mathrm{Pg})$, fats $(\mathrm{Fg})$ and carbohydrates $(\mathrm{Cg})$ at a particular energy value equivalent.

$\mathrm{Wg}(\mathrm{EVE})=\operatorname{Pg}(\mathrm{EVE})+\mathrm{Fg}(\mathrm{EVE})+\mathrm{Cg}(\mathrm{EVE})$ 


\section{RESULTS}

With deviation EVE approaching zero (Table 19), the relative weights of protein, fats and carbohydrates for colza and soybean can be found, and they appear on the interpolation line. The analysis of the graph (Figure 3) clearly shows that the proportion of energy value equivalent to the relative dry weight is a constant figure that equals 1.017. It means that the conservation law of energy is true for the plant world. In other words, the proportion of energy value to the relative dry weight of a plant is a constant figure that is approximately $4,169.79 \mathrm{kcal} / \mathrm{kg}$ of relative dry weight or $17.5 \mathrm{MJ} / \mathrm{kg}$ of the given dry weight, with the energy value of plants calculated by the relative protein, fat and carbohydrate weights being the same as the actual amount of protein, fats and carbohydrates.

Since the conservation law of energy unites all plants into one rigid mathematical system, it is time to find the link between the biochemical composition and the need in mineral nutrients.

Photosynthesis is the only process for the plants to accumulate energy. Photosynthesis product is the carbohydrates, which are then transformed into fats or protein depending on the intrinsic genetic information under the enzymes influence.

The main weight of plants consists of macroelements: carbon, oxygen, hydrogen, nitrogen, phosphorous, potassium. Carbon, oxygen and hydrogen get into a plant from the atmosphere in the form of carbon dioxide or from the soil and atmosphere in the form of moisture. Nitrogen, phosphorous, potassium gets mainly from the soil. However, the sufficient amount of macroelements in the soil does not provide the adequate plant growth, there is a need in mesoelements (sulfur, calcium, magnesium) and microelements (iron, copper, manganese, boracium, zinc, molybdenum, cobalt, etc.). Microelements are minor in plants, but they are very important as they involved in biochemical processes. About a quarter of all known enzymes need the microelements to show their full catalytic effect, without these microelements many enzymes are non-active. Mesoelements are intermediary between the micro- and macroelements in their content in plants and are the parts of both the main weight of a plant and the enzyme composition.

To explore all those biochemical processes it is necessary to analyze and to identify the links between the protein, fats and carbohydrates, and macro-, meso- and microelements.

\section{Macroelement - Nitrogen}

It has already been said above that the content of nitrogen in plants is $16 \%$ of weight of protein and nonprotein compounds (Smirnov and Muravin, 1977)..

Macroelement - Phosphorous 
Phosphorous is one of the main macroelements. The graph (Figure 4) clearly shows that despite the deviations the need in phosphorous among the presented crops is linearly dependent on the energy value of a plant. The deviations are determined by the difficulty to accurately identify the plant's need in P2O5.

Macroelement - Potassium

The need in potassium as the need in phosphorous is linearly dependent on energy value, as it is seen at the graph (Figure 5). Linear dependences of need in potassium and phosphorous on energy value of plant make us assume that these elements directly involved in photosynthesis.

The need in nitrogen, phosphorous and potassium is given for all crops per all plants' weight but if one wants to find the content of macro- and microelements in all plants' weight, one needs to carry out a large-scale expensive research, while the data in the Internet is very controversial. The initial data has the content of microelements in fruits, therefore we will find the link with the biochemical composition of fruits.

Mesoelement - Sulfur

The content of sulfur as the content of potassium and phosphorous is linearly dependent on energy value (Figure 6). This dependence of sulfur content also indicates that the sulfur is very active in participating in photosynthesis.

Mesoelement - Calcium

The graph (Figure 7) shows that the calcium content depends on the fat weight in fruits. Calcium plays an important role in metabolism regulation in a plant cell.

As the calcium is transported very slowly along the plant, this element tends to be accumulated in the older parts of plants. This explains the deviations we see in the graph.

Mesoelement - Magnesium

The content of magnesium is linearly connected with the sum of protein and fat weight. Magnesium is a cofactor for nearly all enzymes, it is a part of chlorophyll, the protein being its ancestor.

Microelements - Copper, Manganese, Zinc, Boracium, Ferrum, Molybdenum, Cobalt

The graphs (figures 9-15) illustrate that all microelements are linearly dependent on either protein weight, or fat weight, or the sum of protein and fat weight. This means that being a part of enzymes they directly involved in protein and fat synthesis.

\section{CONCLUSIONS}

The results of this work can be checked only with a large-scale and expensive research but if we assume that for all plants the dependence between the biochemical composition and 
nutrients is preserved, then their accuracy is quite enough to describe the link between nearly all substances formed in a plant and all range of nutrients. The obtained formulas can help to specify Liebig's law of limiting factor for each nutrient and to quantify it. This fact is as important for agrochemistry as Mendeleev's periodic law for chemistry. When we know the whole need in mineral substances, we can obtain the yield limited by an amount of carbon dioxide in atmosphere and sun energy, and it is difficult to guess the limit of the maximum yield.

Vasilii Grigorevich MINEEV, the Head of the Agrochemistry and Biochemistry Department in M.V. Lomonosov Moscow State University, gave the following answer to the question "What role does agrochemistry play in modern agriculture?" from a journalist:

"... I believe that agrochemistry is the core of the modern agriculture. The civilized and industry-developed countries rely on it in developing their performance and quality, while here our country thinks that the fertilizers are unreasonably expensive and we can do without them. West European countries use about 300, 400 and sometimes up to 500 kilos of nutrients per a hectare. In China this figure is up to 500. This country annually produces up to 50 million tons of fertilizers, which are used in agriculture, they even buy from foreign countries. Russia produces about 20 million tons of fertilizers but only two millions are used. The rest goes abroad. Our agriculture is kept on short rations".

To change the belief about the fertilizer usage in Russia, it is necessary to understand that their effective use increases the yield capacity, reduces the overall expenditures (farming, etc.), results in increase of production profitability and contributes into the problem solution to provide the growing number of population with food.

Since the dependences of plants' needs in nutrients on biochemical composition have been identified, then the agrochemistry can be considered to be both a quantitative, and descriptive, and qualitative science.

The accurate knowledge about the plants' needs in mineral nutrients comes close to the solution but does not answer all the questions about the increase of yield capacity. It is important both to know the amount of the necessary elements and to provide these elements to plants in an appropriate way. 


\section{REFERENCES}

Adamenko, S. and Kostyushko. I. n.d. Podkormka soi i podsolnechnika. [Soybean and sunflower top dressing] OOO «VITERA UKRAINA».

Biologicheskie osobennosti rapsa [Colza biological peculiarities]. 2015.

http://biofile.ru/bio/18505.html. Accessed on September 1, 2015.

Chto soderzhitsya v kapuste belokochannoy? [What does cabbage contain?]. 2011. Zdorovoe pitanie. http://edazdorov.ru/poleznii-produkt/ovosh/439-cto-soderzitsa-v-kapuste-belokac.html. Accessed on September 1, 2015.

Chto soderzhitsya v kartofele? [What does potato contain?]. 2011.

http://edazdorov.ru/poleznii-produkt/ovosh/447-cto-soderzitsa-v-kartofele-.html. Accessed on September 1, 2015.

Chto soderzhitsya v pshenitse? [What does wheat contain?]. 2011. http://edazdorov.ru/poleznii-produkt/zlaki/281-cto-soderzitsa-v-psenice-.html. Accessed on September 1, 2015.

Chto soderzhitsya v soe? [What does soybean contains?].2011. http://edazdorov.ru/polezniiprodukt/specii/568-cto-soderzitsa-v-soe.html. Accessed on September 1, 2015.

Dieta Online [Diet Online]. 2009. http://www.dietaonline.ru/myhome/nutrition.php Accessed on September 1, 2015.

Fedotova L.S. 2015. Kak pravil'no primenyat' udobreniya pod kartofel'? [How to fertilize the potato properly?]. http://www.mikrovit.ru/files/statia/st4.doc. Accessed on September 1, 2015.

Himicheskiy sostav i pitatel'nost' kormov po regionam Rossii i vidam.[Chemical composition and nutritive value of feed according to regions of Russia]. n.d. Korma Rossii. http://vidkormov.narod.ru/typ2/s1.html. Accessed on September 1, 2015.

Isupova, Yu.A. 2013. Ocenka deystviya mineral'nyh udobreniy na posevah soi, vozdelyvaemoy na chernozeme vyschelochennom zapadnogo predkavkaz'ya [Estimation of mineral fertilizers effect on the basis of soybean seeding cultivated in leached chernozem of Ciscaucasia]. Proceeding of 7-th International Conference of the Young Scientists and Experts. Krasnodar: 100-104.

Kakie vitaminy i mikroelementy soderzhatsya v luke? [What vitamins and microelements does bulb onion contain]. 2013. http://kakievitaminy.ru/produkty/vitaminy-v-luke. Accessed on September 1, 2015.

Kartofel' [Potato]. n.d. https://ru.wikipedia.org/wiki/Kartofel'. Accessed on September 1, 2015. 
Kartofel' - kaloriynost', himicheskiy sostav, pishhevaya tsennost' [Potato - Caloricity, chemical composition, nutritive value]. 2015. http://www.tiptip.ru/p/10/kartofel/. Accessed on September 1, 2015.

Kulakov V.A. 2009. Raps [Colza]. http://www.epitanie.ru/rastitelnie_masla/rapsovoe_maslo.php. Accessed on September 1, 2015. Makarov V.I. 2014. Osobennosti rascheta normativov vynosa elementov pitaniya zernovymi kul"turami [Peculiarities of calculation of standards for nutrition elements removal by cereal crops. Agronomiya 5(115): 9-13.

Metody rascheta norm udobreniy i sostavlenie rekomendaciy i proektno-smetnoy dokumentacii po ih primeneniyu [Calculation methods for fertilizers amounts and development of recommendations and design estimation documentation for their application]. 2001 http://agrolib.ru/books/item/f00/s00/z0000019/st037.shtml. Accessed on September 1, 2015.

Mineev V.G. Mikroelementy [MIcroelements]. n.d. http://tinref.ru/000_uchebniki/04800selskoe_hozaistvo/000_agrohimia_mineev/028.htm. Accessed on September 1, 2015.

Nechaeva, T.B. and Bykova, S.L. 2014. Role of agrochemistry of in the context of modern farming in Russia Zhivye i biokosnye sistemy 7: 2-7.

Osnovnoe vnesenie udobreniy [Basal fertilizing]. n.d.

http://www.ovoschevodstvo.ru/tomat/osnovnoe-vnesenie-udobrenii.html. Accessed on September 1, 2015.

Podkolzin A.I. Burlazin A.V. 1988. Opyt vyraschivaniya ozdorovlennogo semennogo kartofelya v OOO ETK «MERISTEMNYE KUL'TURY» [The experience of sanitated plant potato growing-up by LLC Experimental Greenhouse Facility “MERISTEMNYE KULTURY']. http://meristema.info/showarticle.html?NewsId=8. Accessed on September 1, 2015.

Podkormka pomidorov [Tomatoes top dressing]. n.d. Lyubimiy sad. http://lovesad.ru/ogorod/1489-podkormka-pomidorov.html. Accessed on September 1, 2015. Potrebnost' kartofelya $\mathrm{v}$ elementah kornevogo pitaniya [The need of potato in root nutrition elements]. 2015. http://fermerland.com/rastenievodstvo/ovoshchevodstvo/korneplodnye-iklubneplodnye-ovoshchi/kartofel/371-potrebnost'-kartofelja-v-jelementah-kornevogopitanija.html. Accessed on September 1, 2015.

Povyshenie urozhaynosti pshenitsy [Wheat productivity increase]. n.d. http:/www.yara.ru/crop-nutrition/crops/wheat/yield/. Accessed on September 1, 2015. 
Research and Production Enterprise "CEOLIT". 1990. Ozimy raps - tekhnologiya vyraschivaniya [Winter rape - cultivation technology].

http://zeolit.com.ua/company/production/tech/100/870/. Accessed on September 1, 2015. Smirnov, P.M. and Muravin, E.A. 1977. Agrohimiya [Agrochemistry].2nd Edition. - Moskva, Russia: KOLOS.

Spitsyna, S.F., Tomarovskiy, A.A. and Ostval'd G.V. 2013. Povedenie Mikroelementov V Sisteme Pochva - Rasteniya Pshenitsy V Razlichnyh Zonah Altayskogo Kraya [Behavior of microelements within the Soil - Wheat plants system in different zones of Altai Krai]. Vestnik Altayskogo gosudarstvennogo agrarnogo universiteta 12(110): 42-47.

Stepuro, M.F. 2012. Sezonnaya dinamika potrebleniya i vynos osnovnyh elementov pitaniya belokochannoy kapustoy [Seasonal dynamics of consumption and removal of fertilizer elements by cabbage]. Minsk, Belarus: Institut prirodopol'zovaniya NAS of Belarus. Tablica kaloriynosti i energeticheskoy cennosti produktov [Table of caloricity and nutritive value of foods]. n.d. Zvezda stranstviy. http://www.zvezdacz.ru/krasota/pitanie/tabl.php. Accessed on September 1, 2015.

Tablitsa soderzhaniya v ovoschah i zeleni vitaminov, mineralov, belkov, uglevodov, kaloriy [The table of vitamins, minerals, proteins, carbohydrates and calories content in vegetables and green] 2015. - http://organic-vitamin.ru/nutrients-in-foods/vegetables-chart.html. Accessed on September 1, 2015.

Udobrenie ovoschnyh kul'tur [Vegetable crops fertilization]. n.d. http://neznaniya.net/agronomija/racionalnoe-primenenie-udobrenij/1995-udobrenieovoschnyh-kultur.html. Accessed on September 1, 2015.

Vasyaev, G. and Vasyaeva O. n.d. Pitanie i udobrenie ogurcov, vyraschivaemyh v teplitsah [Nutrition and fertilize of cucumbers grown up in greenhouses].

http://www.floraprice.ru/articles/ogorod/udobrenie-v-teplicax-2.html. Accessed on September $1,2015$.

Vynos pitatel'nyh veschestv ovoschnymi i kormovymi kul'turami [Removal of nutrients by vegetable and feed crops]. n.d. http://biofile.ru/bio/18515.html. Accessed on September 1, 2015.

Vyraschivanie rasteniy bez pochvy [Plants cultivation without soil]. 2015. Komnatnye rasteniya. http://www.prostoflora.ru/bezpochvy/16.html. Accessed on September 1, 2015. Yadrov. S.V. 2009a. Kaloriynost' Luk repchatyy. Himicheskiy sostav i pischevaja tsennost'. [Caloricity - Bulb onion. Chemical composition and nutrition value]. http://healthdiet.ru/base_of_food/sostav/186.php. Accessed on September 1, 2015. 
Yadrov S.V. 2009b. Kaloriynost' Morkov', zheltaya. Himicheskiy sostav i pischevaja tsennost'. [Caloricity. Yellow carrot. Chemical compound and nutrition value]. http://healthdiet.ru/base_of_food/sostav/805.php. Accessed on September 1, 2015.

Yadrov S.V. 2009c. Kaloriynost' Ogurets, parnikovy. Himicheskiy sostav i pischevaja tsennost'. [Caloricity. Frame cucumber. Chemical compound and nutritive value]. http://health-diet.ru/base_of_food/sostav/807.php. Accessed on September 1, 2015. Yadrov S.V. 2009d. Kaloriynost' Pomidory (tomaty). Himicheskiy sostav i pishhevaya cennost'. [Tomatoes caloricity. Chemical composition and nutritive value]. http://healthdiet.ru/base_of_food/sostav/397.php. Accessed on September 1, 2015. Yadrov S.V. 2009e. Kaloriynost' Svekla. Himicheskiy sostav i pishhevaya cennost'. [Caloricity. Beetroot. Chemical composition and nutritive value]. http://healthdiet.ru/base_of_food/sostav/325.php. Accessed on September 1, 2015. Yadrov S. V. 2009f. Kaloriynost' Zerno tverdoy pshenitsy. Himicheskiy sostav i pishhevaya cennost'. [Caloricity. Durum wheat. Chemical composition and nutritive value], http://healthdiet.ru/base of food/sostav/291.php. Accessed on September 1, 2015.

Zharkov, V.A. and Kalashnikov, A.A. 2015. Rezhimy orosheniya i mineral'nogo pitaniya luka pri kapel'nom polive [Schedule of irrigation and mineral nutrition for drip watering]. http://www.rusnauka.com/24_NNP_2013/Agricole/1_143497.doc.htm. Accessed on September 1, 2015. 


\section{Tables}

Table 1. Cabbage. Biochemical composition of fruits, yield capacity and need in nutrients.

\begin{tabular}{|c|c|c|c|c|c|c|c|c|}
\hline \multirow[b]{2}{*}{ \# } & \multirow[b]{2}{*}{ Indicator } & \multicolumn{6}{|c|}{ Source } & \multirow{2}{*}{$\begin{array}{l}\text { Average } \\
\text { value of } \\
\text { indicator, } \\
\mathrm{gr} / \mathrm{kg} \text { of } \\
\text { yield }\end{array}$} \\
\hline & & {$[1]$} & {$[1]$} & {$[2]$} & {$[3]$} & {$[4]$} & {$[5]$} & \\
\hline 1 & Protein, gr & & & 1.8 & & 1.2 & 1.28 & 14.27 \\
\hline 2 & Fats, gr & & & 0.1 & & 0.2 & & 1.50 \\
\hline 3 & Carbohydrates, gr & & & 4.7 & & 5.4 & 5.8 & 53.00 \\
\hline 4 & Dietary fibers, gr & & & & & 2.3 & & 23.00 \\
\hline 5 & Yield capacity, kg & 70 & 70 & 0.1 & 10 & 0.1 & 0.1 & 1.00 \\
\hline 6 & $\mathrm{~N}$, gr & 250 & 230 & & 40.8 & & & 3.65 \\
\hline 7 & $\mathrm{P} 2 \mathrm{O} 5, \mathrm{gr}$ & 39.6 & 38.7 & 0.071 & 11.2 & 0.526 & 0.06 & 1.47 \\
\hline 8 & $\mathrm{~K} 2 \mathrm{O}$, gr & 249 & 253 & 0.361 & 41.9 & 0.296 & 0.204 & 3.33 \\
\hline 9 & $\mathrm{~S}, \mathrm{gr}$ & & & 0.037 & & & & 0.370 \\
\hline 10 & $\mathrm{Ca}, \mathrm{gr}$ & 248 & 298 & 0.048 & & 0.047 & 0.04 & 1.83 \\
\hline 11 & $\mathrm{Mg}, \mathrm{gr}$ & & & 0.016 & & 0.015 & 0.012 & 0.14 \\
\hline 12 & $\mathrm{Cu}, \mathrm{gr}$ & & & 0.000075 & & & 0.000019 & 0.00047 \\
\hline 13 & $\mathrm{Mn}, \mathrm{gr}$ & & & 0.00017 & & 0.0002 & 0.00016 & 0.0018 \\
\hline 14 & $\mathrm{Zn}, \mathrm{gr}$ & & & 0.0004 & & 0.0002 & 0.00018 & 0.0026 \\
\hline 15 & $\mathrm{~B}, \mathrm{gr}$ & & & 0.0002 & & & & 0.0020 \\
\hline 16 & $\mathrm{Fe}, \mathrm{gr}$ & & & 0.0006 & & 0.0006 & 0.00047 & 0.0056 \\
\hline 17 & Mo, gr & & & 0.00001 & & & & 0.00010 \\
\hline 18 & Co, gr & & & 0.000003 & & & & 0.000030 \\
\hline
\end{tabular}

Note for Tables 1-10.

Value for "Average value of indicator, gr $/ \mathrm{kg}$ of yield" is an average value of an indicator preliminary divided by the yield capacity (column 5), for all sources.

The columns numbered [1], [2], [3], [4], [5] refer to (Vyraschivanie rasteniy..., 2015), (Chto soderzhitsya v kapuste..., 2011), (Stepuro, 2012), (Dieta Online, 2009), (Tablitsa soderzhaniya..., 2015) respectively. 
Table 2. Potato. Biochemical composition of fruits, yield capacity and need in nutrients

\begin{tabular}{|c|c|c|c|c|c|c|c|c|c|c|}
\hline \multirow[b]{2}{*}{ \# } & \multirow[b]{2}{*}{ Indicator } & \multicolumn{8}{|c|}{ Source } & \multirow{2}{*}{$\begin{array}{l}\text { Average } \\
\text { value of } \\
\text { indicator, } \\
\mathrm{gr} / \mathrm{kg} \text { of } \\
\text { yield }\end{array}$} \\
\hline & & {$[1]$} & {$[1]$} & {$[6]$} & {$[7]$} & {$[8]$} & [9] & [10] & [11] & \\
\hline 1 & Protein, gr & & & 2 & & & 2 & & 1.9 & 19.67 \\
\hline 2 & Fats, gr & & & 0.4 & & & 0.4 & & 0.1 & 3.00 \\
\hline 3 & Carbohydrates, gr & & & 16.3 & & & 16 & & 16.6 & 163.00 \\
\hline 4 & Dietary fibers, gr & & & 1.4 & & & & & 1.8 & 16.00 \\
\hline 5 & Yield capacity, kg & 30.6 & 15 & 0.1 & 22.5 & 0.1 & 0.1 & 10 & 0.1 & 1.00 \\
\hline 6 & $\mathrm{~N}, \mathrm{gr}$ & 125 & 84 & & 112.5 & 0.62 & & 47.5 & & 5.13 \\
\hline 7 & $\mathrm{P} 2 \mathrm{O} 5, \mathrm{gr}$ & 14 & 18 & 0.132 & 45 & 0.3 & 0.132 & 16.5 & 0.135 & 1.54 \\
\hline 8 & $\mathrm{~K} 2 \mathrm{O}$, gr & 133.6 & 153 & 0.684 & 170 & 1.45 & 0.684 & 65 & 0.513 & 7.74 \\
\hline 9 & $\mathrm{~S}$, gr & & & 0.032 & & & 0.032 & & & 0.32 \\
\hline 10 & $\mathrm{Ca}, \mathrm{gr}$ & & 74 & 0.01 & & & 0.01 & & 0.011 & 1.31 \\
\hline 11 & $\mathrm{Mg}$, gr & & & 0.023 & & & 0.023 & 9 & 0.022 & 0.40 \\
\hline 12 & $\mathrm{Cu}, \mathrm{gr}$ & & & 0.00014 & & & 0.00014 & & & 0.0014 \\
\hline 13 & Mn, gr & & & 0.00017 & & & 0.00017 & & & 0.0017 \\
\hline 14 & $\mathrm{Zn}, \mathrm{gr}$ & & & 0.00036 & & & 0.00036 & & & 0.0036 \\
\hline 15 & $\mathrm{~B}, \mathrm{gr}$ & & & 0.000115 & & & 0.000115 & & & 0.0012 \\
\hline 16 & $\mathrm{Fe}, \mathrm{gr}$ & & & 0.0009 & & & 0.0009 & & 0.0007 & 0.0083 \\
\hline 17 & Mo, gr & & & 0.000008 & & & 0.000008 & & & 0.00008 \\
\hline 18 & Co, gr & & & 0.0000005 & & & 0.000005 & & & 0.000028 \\
\hline
\end{tabular}

The columns numbered [1], [6], [7], [8], [9], [10], [11] refer to (Vyraschivanie rasteniy..., 2015), (Kartofel' - kaloriynost'..., 2015), (Potrebnost' kartofelya..., 2015), (Fyodorova, 2015), (Chto soderzhitsya v kartofele?, 2011), (Podkolzin and Burlazin, 1988), (Kartofel', n.d.) respectively. 
Table 3. Bulb onion. Biochemical composition of fruits, yield capacity and need in nutrients

\begin{tabular}{|c|c|c|c|c|c|c|c|}
\hline \multirow[b]{2}{*}{$\#$} & \multirow[b]{2}{*}{ Indicator } & \multicolumn{5}{|c|}{ Source } & \multirow{2}{*}{$\begin{array}{l}\text { Average } \\
\text { value of } \\
\text { indicator, } \\
\mathrm{gr} / \mathrm{kg} \text { of } \\
\text { yield }\end{array}$} \\
\hline & & [12] & {$[13]$} & {$[4]$} & {$[14]$} & {$[5]$} & \\
\hline 1 & Protein, gr & & 1.4 & 1.1 & 1.4 & 1.1 & 12.50 \\
\hline 2 & Fats, gr & & 0.2 & 0.1 & 0.2 & & 1.67 \\
\hline 3 & Carbohydrates, gr & & 8.2 & 9.3 & 8.2 & 9.34 & 87.60 \\
\hline 4 & Dietary fibers, gr & & 3 & 1.7 & 3 & 1.7 & 23.50 \\
\hline 5 & Yield capacity, kg & 10 & 0.1 & 0.1 & 0.1 & 0.1 & 1.00 \\
\hline 6 & $\mathrm{~N}, \mathrm{gr}$ & 44 & & & & & 4.40 \\
\hline 7 & $\mathrm{P} 2 \mathrm{O} 5, \mathrm{gr}$ & 12 & 0.132 & 0.066 & 0.132 & 0.066 & 1.03 \\
\hline 8 & $\mathrm{~K} 2 \mathrm{O}$, gr & 21 & 0.21 & 0.176 & 0.21 & 0.175 & 1.96 \\
\hline 9 & $\mathrm{~S}$, gr & & 0.065 & & 0.065 & & 0.65 \\
\hline 10 & $\mathrm{Ca}, \mathrm{gr}$ & 5 & 0.031 & 0.023 & 0.031 & 0.023 & 0.32 \\
\hline 11 & $\mathrm{Mg}, \mathrm{gr}$ & 2.4 & 0.014 & 0.01 & 0.014 & 0.01 & 0.14 \\
\hline 12 & $\mathrm{Cu}, \mathrm{gr}$ & & 0.000085 & & & 0.000039 & 0.00062 \\
\hline 13 & $\mathrm{Mn}, \mathrm{gr}$ & & 0.00023 & 0.0001 & & 0.000129 & 0.0015 \\
\hline 14 & $\mathrm{Zn}, \mathrm{gr}$ & & 0.00085 & 0.0002 & & 0.00017 & 0.0041 \\
\hline 15 & $\mathrm{~B}, \mathrm{gr}$ & & 0.0002 & & & & 0.0020 \\
\hline 16 & $\mathrm{Fe}, \mathrm{gr}$ & & 0.0008 & 0.0002 & & 0.00021 & 0.0040 \\
\hline 17 & Mo, gr & & 0.000012 & & & & 0.00012 \\
\hline 18 & $\mathrm{Co}, \mathrm{gr}$ & & 0.000005 & & & & 0.00005 \\
\hline
\end{tabular}


The columns numbered [4], [5], [12], [13], [14] refer to (Dieta Online, 2009), (Tablitsa soderzhaniya..., 2015), (Zharkov and Kalashnikov, 2015), (Yadrov, 2009a), (Kakie vitanimy i mikroelementy..., 2013) respectively.

Table 4. Carrot. Biochemical composition of fruits, yield capacity and need in nutrients

\begin{tabular}{|c|c|c|c|c|c|}
\hline \multirow[b]{2}{*}{$\#$} & \multirow[b]{2}{*}{ Indicator } & \multicolumn{3}{|c|}{ Source } & \multirow{2}{*}{$\begin{array}{c}\text { Average } \\
\text { value of } \\
\text { indicator, } \\
\text { gr/kg of yield }\end{array}$} \\
\hline & & {$[15]$} & {$[16]$} & {$[5]$} & \\
\hline 1 & Protein, gr & & 1.3 & 0.93 & 11.15 \\
\hline 2 & Fats, gr & & 0.1 & & 1.00 \\
\hline 3 & Carbohydrates, gr & & 7.2 & 9.58 & 83.90 \\
\hline 4 & Dietary fibers, gr & & 0.8 & 2.8 & 18.00 \\
\hline 5 & Yield capacity, kg & 1 & 0.1 & 0.1 & 1.00 \\
\hline 6 & $\mathrm{~N}, \mathrm{gr}$ & 3.2 & & & 3.20 \\
\hline 7 & $\mathrm{P} 2 \mathrm{O} 5, \mathrm{gr}$ & 1 & 0.137 & 0.08 & 1.06 \\
\hline 8 & $\mathrm{~K} 2 \mathrm{O}$, gr & 5 & 0.282 & 0.385 & 3.89 \\
\hline 9 & $\mathrm{~S}, \mathrm{gr}$ & & 0.006 & & 0.06 \\
\hline 10 & $\mathrm{Ca}, \mathrm{gr}$ & & 0.046 & 0.033 & 0.40 \\
\hline 11 & $\mathrm{Mg}, \mathrm{gr}$ & & 0.036 & 0.012 & 0.24 \\
\hline 12 & $\mathrm{Cu}, \mathrm{gr}$ & & 0.00008 & 0.000045 & 0.00063 \\
\hline 13 & $\mathrm{Mn}, \mathrm{gr}$ & & 0.0002 & 0.000143 & 0.0017 \\
\hline 14 & $\mathrm{Zn}, \mathrm{gr}$ & & 0.0004 & 0.00024 & 0.0032 \\
\hline 15 & $\mathrm{~B}, \mathrm{gr}$ & & 0.0002 & 0.0003 & 0.0025 \\
\hline 16 & $\mathrm{Fe}, \mathrm{gr}$ & & 0.0014 & & 0.014 \\
\hline
\end{tabular}




\begin{tabular}{|r|l|r|l|l|}
\hline 17 & Mo,gr & & 0.00002 & \\
\hline 18 & Co,gr & 0.000002 & 0.00020 \\
\hline
\end{tabular}

The columns numbered [5], [15], [16] refer to (Tablitsa soderzhaniya, 2015), (Vynos pitatel'nyh veschestv..., n.d.), (Yadrov, 2009b) respectively.

Table 5. Cucumber. Biochemical composition of fruits, yield capacity and need in nutrients

\begin{tabular}{|c|c|c|c|c|c|c|c|}
\hline \multirow[b]{2}{*}{ \# } & \multirow[b]{2}{*}{ Indicator } & \multicolumn{5}{|c|}{ Source } & \multirow{2}{*}{$\begin{array}{l}\text { Average } \\
\text { value of } \\
\text { indicator, } \\
\mathrm{gr} / \mathrm{kg} \text { of } \\
\text { yield }\end{array}$} \\
\hline & & {$[1]$} & {$[1]$} & [1] & {$[17]$} & [18] & \\
\hline 1 & Protein, gr & - & & & 0.7 & & 7.00 \\
\hline 2 & Fats, gr & & & & 0.1 & & 1.00 \\
\hline 3 & Carbohydrates, gr & & & & 1.9 & & 19.00 \\
\hline 4 & Dietary fibers, gr & & & & 0.7 & & 7.00 \\
\hline 5 & Yield capacity, kg & 20.9 & 20.9 & 20 & 0.1 & 1 & 1.00 \\
\hline 6 & $\mathrm{~N}, \mathrm{gr}$ & 51 & 109 & 37 & & 2.64 & 3.04 \\
\hline 7 & $\mathrm{P} 2 \mathrm{O} 5, \mathrm{gr}$ & 18 & 15.9 & 8.8 & 0.687 & 1.55 & 2.10 \\
\hline 8 & $\mathrm{~K} 2 \mathrm{O}$, gr & 64.7 & 85.5 & 78.8 & 0.236 & 6.6 & 4.02 \\
\hline 9 & $\mathrm{~S}$, gr & & & & & & - \\
\hline 10 & $\mathrm{Ca}, \mathrm{gr}$ & 19 & & 26.2 & 0.017 & & 0.80 \\
\hline 11 & $\mathrm{Mg}$, gr & & & & 0.014 & & 0.14 \\
\hline 12 & $\mathrm{Cu}, \mathrm{gr}$ & & & & 0.0001 & & 0.0010 \\
\hline 13 & $\mathrm{Mn}$, gr & & & & 0.00018 & & 0.0018 \\
\hline 14 & $\mathrm{Zn}, \mathrm{gr}$ & & & & 0.000215 & & 0.0022 \\
\hline
\end{tabular}




\begin{tabular}{|c|c|c|c|}
\hline 15 & $\mathrm{~B}, \mathrm{gr}$ & & - \\
\hline 16 & $\mathrm{Fe}, \mathrm{gr}$ & 0.0005 & 0.0050 \\
\hline 17 & Mo, gr & 0.000001 & 0.000010 \\
\hline 18 & $\mathrm{Co}, \mathrm{gr}$ & 0.000001 & 0.000010 \\
\hline
\end{tabular}

The columns numbered [1], [17], [18] refer to (Vyraschivanie rasteniy, 2015), (Yadrov, 2009c), (Vasyaev and Vasyaeva, n.d.) respectively.

Table 6. Wheat. Biochemical composition of fruits, yield capacity and need in nutrients

\begin{tabular}{|c|c|c|c|c|c|c|c|}
\hline \multirow[b]{2}{*}{ \# } & \multirow[b]{2}{*}{ Indicator } & \multicolumn{6}{|c|}{ Source } \\
\hline & & [19] & [19] & {$[20]$} & [21] & {$[21]$} & [22] \\
\hline 1 & Protein, gr & & & & & & \\
\hline 2 & Fats, gr & & & & & & \\
\hline 3 & Carbohydrates, gr & & & & & & \\
\hline 4 & Dietary fibers, gr & & & & & & \\
\hline 5 & Yield capacity, kg & 1 & 1 & 0.1 & 2.7 & 3.8 & 1 \\
\hline 6 & $\mathrm{~N}, \mathrm{gr}$ & 28 & & & & & \\
\hline 7 & $\mathrm{P} 2 \mathrm{O} 5, \mathrm{gr}$ & 5.2 & & 0.842 & & & \\
\hline 8 & $\mathrm{~K} 2 \mathrm{O}$, gr & 18 & & 0.392 & & & \\
\hline 9 & $\mathrm{~S}$, gr & 3.1 & 4.4 & 0.1 & & & \\
\hline 10 & $\mathrm{Ca}, \mathrm{gr}$ & & 3 & 0.062 & & & \\
\hline 11 & $\mathrm{Mg}, \mathrm{gr}$ & 2.6 & 3 & 0.114 & & & \\
\hline 12 & $\mathrm{Cu}, \mathrm{gr}$ & & 0.01 & 0.00053 & 0.02 & 0.02 & 0.015 \\
\hline 13 & $\mathrm{Mn}, \mathrm{gr}$ & & 0.07 & 0.0037 & 0.161 & 0.292 & 0.14 \\
\hline
\end{tabular}




\begin{tabular}{|l|l|l|l|l|l|l|l|}
14 & Zn, gr & & 0.052 & 0.00281 & 0.148 & 0.158 & 0.07 \\
\hline 15 & B, gr & & 0.025 & & & & 0.005 \\
\hline 16 & Fe, gr & & 0.137 & 0.0053 & & & \\
\hline 17 & Mo, gr & & & 0.000042 & 0.0001 & 0.00054 & 0.0009 \\
\hline 18 & Co, gr & & & 0.0000054 & & & 0.0004 \\
\hline
\end{tabular}

The columns numbered [19], [20], [21], [22] refer to (Povyshenie urozhaynosti..., n.d.), (Chto soderzhitsya v pshenitse?, 2011), (Mineev, n.d), (Spitsyna et at., 2013) respectively.

Table 7. (continued). Wheat. Biochemical composition of fruits, yield capacity and need in nutrients

\begin{tabular}{|c|c|c|c|c|c|c|c|}
\hline \multirow[b]{2}{*}{ \# } & \multirow[b]{2}{*}{ Indicator } & \multicolumn{5}{|c|}{ Source } & \multirow{2}{*}{$\begin{array}{l}\text { Average } \\
\text { value of } \\
\text { indicator, } \\
\mathrm{gr} / \mathrm{kg} \text { of } \\
\text { yield }\end{array}$} \\
\hline & & [23] & [23] & [24] & {$[4]$} & [25] & \\
\hline 1 & Protein, gr & & & & 11.3 & 13 & 121.50 \\
\hline 2 & Fats, gr & & & & 1.7 & 2.5 & 6.53 \\
\hline 3 & Carbohydrates, gr & & & & 75.9 & 57.5 & 667.00 \\
\hline 4 & Dietary fibers, gr & & & & 11.2 & 11.3 & 112.50 \\
\hline 5 & Yield capacity, kg & 1 & 1 & 1 & 0.1 & 0.1 & 1.00 \\
\hline 6 & $\mathrm{~N}, \mathrm{gr}$ & 30 & 5 & 28.1 & & & 22.78 \\
\hline 7 & $\mathrm{P} 2 \mathrm{O} 5, \mathrm{gr}$ & 13 & 12 & 11.6 & 0.812 & 0.842 & 9.54 \\
\hline 8 & $\mathrm{~K} 2 \mathrm{O}$, gr & 25 & 25 & 22.8 & 0.52 & 0.391 & 14.83 \\
\hline 9 & $\mathrm{~S}, \mathrm{gr}$ & & & & & 0.1 & 2.38 \\
\hline 10 & $\mathrm{Ca}$, gr & & & & 0.032 & 0.062 & 1.14 \\
\hline 11 & $\mathrm{Mg}$, gr & & & & & 0.114 & 1.97 \\
\hline
\end{tabular}




\begin{tabular}{|c|c|c|c|c|}
\hline 12 & $\mathrm{Cu}, \mathrm{gr}$ & 0.0004 & 0.00053 & 0.0075 \\
\hline 13 & Mn, gr & 0.0038 & 0.0037 & 0.065 \\
\hline 14 & $\mathrm{Zn}, \mathrm{gr}$ & 0.0033 & 0.00281 & 0.044 \\
\hline 15 & $\mathrm{~B}, \mathrm{gr}$ & & & 5.00 \\
\hline 16 & $\mathrm{Fe}, \mathrm{gr}$ & 0.0046 & 0.0053 & 0.072 \\
\hline 17 & Mo, gr & & 0.000042 & 0.00038 \\
\hline 18 & $\mathrm{Co}, \mathrm{gr}$ & & & 0.00023 \\
\hline
\end{tabular}

The columns numbered [4], [23], [24], [25], refer to (Dieta Online, 2009), (Metody rascheta norm..., 2001), (Makarov, 2014), (Yadrov, 2009f) respectively.

Table 8. Colza. Biochemical composition of fruits, yield capacity and need in nutrients

\begin{tabular}{|c|c|c|c|c|c|}
\hline \multirow[b]{2}{*}{ \# } & \multirow[b]{2}{*}{ Indicator } & \multicolumn{3}{|c|}{ Source } & \multirow{2}{*}{$\begin{array}{l}\text { Average value } \\
\text { of indicator, } \\
\mathrm{gr} / \mathrm{kg} \text { of yield }\end{array}$} \\
\hline & & {$[26]$} & {$[27]$} & [28] & \\
\hline 1 & Protein, gr & & 24.5 & & 245.00 \\
\hline 2 & Fats, gr & & 42.5 & & 425.00 \\
\hline 3 & Carbohydrates, gr & & 6 & & 60.00 \\
\hline 4 & Dietary fibers, gr & & & & - \\
\hline 5 & Yield capacity, kg & 1 & 0.1 & 1 & 1.00 \\
\hline 6 & $\mathrm{~N}, \mathrm{gr}$ & 50 & & 51 & 50.50 \\
\hline 7 & $\mathrm{P} 2 \mathrm{O} 5, \mathrm{gr}$ & 24 & & 23.5 & 23.75 \\
\hline 8 & $\mathrm{~K} 2 \mathrm{O}$, gr & 60 & & 37.5 & 48.75 \\
\hline 9 & $\mathrm{~S}$, gr & 20 & & & 20.00 \\
\hline 10 & $\mathrm{Ca}, \mathrm{gr}$ & 60 & & & 60.00 \\
\hline 11 & $\mathrm{Mg}, \mathrm{gr}$ & 10 & & & 10.00 \\
\hline
\end{tabular}




\begin{tabular}{|l|l|l|l|l|l|}
\hline 12 & $\mathrm{Cu}, \mathrm{gr}$ & 0.04 & & & 0.04 \\
\hline 13 & Mn, gr & 0.1 & & 1.05 & 0.58 \\
\hline 14 & Zn, gr & 0.15 & & & 0.15 \\
\hline 15 & B, gr & 0.06 & & 0.1 & 0.080 \\
\hline 16 & Fe, gr & 0.36 & & & 0.36 \\
\hline 17 & Mo, gr & 0.002 & & 0.0105 & 0.0063 \\
\hline 18 & Co, gr & & & & - \\
\hline
\end{tabular}

The columns numbered [26], [27], [28] refer to (Research and Production Enterprise “CEOLIT”, 1990), (Kulakov, 2009), (Biologicheskie osobennosti rapsa, 2015) respectively.

Table 9. Beetroot. Biochemical composition of fruits, yield capacity and need in nutrients

\begin{tabular}{|c|c|c|c|c|c|}
\hline \multirow[b]{2}{*}{ \# } & \multirow[b]{2}{*}{ Indicator } & \multicolumn{3}{|c|}{ Source } & \multirow{2}{*}{$\begin{array}{l}\text { Average } \\
\text { value of } \\
\text { indicator, } \\
\mathrm{gr} / \mathrm{kg} \text { of yield }\end{array}$} \\
\hline & & {$[1]$} & [29] & {$[30]$} & \\
\hline 1 & Protein, gr & & 1.5 & & 15.00 \\
\hline 2 & Fats, gr & & 0.1 & & 1.00 \\
\hline 3 & Carbohydrates, gr & & 8.8 & & 88.00 \\
\hline 4 & Dietary fibers, gr & & 2.5 & & 25.00 \\
\hline 5 & Yield capacity, kg & 20 & 0.1 & 10 & 1.00 \\
\hline 6 & $\mathrm{~N}, \mathrm{gr}$ & 80 & & 27 & 3.35 \\
\hline 7 & $\mathrm{P} 2 \mathrm{O} 5, \mathrm{gr}$ & 15.4 & 0.098 & 15 & 1.08 \\
\hline 8 & $\mathrm{~K} 2 \mathrm{O}, \mathrm{gr}$ & 103.7 & 0.346 & 43 & 4.32 \\
\hline 9 & $\mathrm{~S}$, gr & & 0.007 & & 0.070 \\
\hline 10 & $\mathrm{Ca}, \mathrm{gr}$ & 21.3 & 0.037 & & 0.72 \\
\hline
\end{tabular}




\begin{tabular}{|c|c|c|c|}
\hline 11 & $\mathrm{Mg}$, gr & 0.022 & 0.22 \\
\hline 12 & $\mathrm{Cu}, \mathrm{gr}$ & 0.00014 & 0.0014 \\
\hline 13 & Mn, gr & 0.00066 & 0.0066 \\
\hline 14 & $\mathrm{Zn}, \mathrm{gr}$ & 0.000425 & 0.0043 \\
\hline 15 & B, gr & 0.00028 & 0.0028 \\
\hline 16 & $\mathrm{Fe}, \mathrm{gr}$ & 0.0014 & 0.014 \\
\hline 17 & Mo, gr & 0.00001 & 0.00010 \\
\hline 18 & $\mathrm{Co}, \mathrm{gr}$ & 0.000002 & 0.000020 \\
\hline
\end{tabular}

The columns numbered [11], [29], [30] refer to (Kartofel', n.d.), (Yadrov, 2009e), (Udobrenie ovoschnyh kul'tur, n.d.) respectively.

Table 10. Soybean. Biochemical composition of fruits, yield capacity and need in nutrients

\begin{tabular}{|c|c|c|c|c|c|}
\hline \multirow[b]{2}{*}{ \# } & \multirow[b]{2}{*}{ Indicator } & \multicolumn{3}{|c|}{ Source } & \multirow{2}{*}{$\begin{array}{l}\text { Average } \\
\text { value of } \\
\text { indicator, } \\
\text { gr/kg of yield }\end{array}$} \\
\hline & & {$[31]$} & [32] & [33] & \\
\hline 1 & Protein, gr & & & 35 & 350.00 \\
\hline 2 & Fats, gr & & & 17 & 170.00 \\
\hline 3 & Carbohydrates, gr & & & 17 & 170.00 \\
\hline 4 & Dietary fibers, gr & & & & - \\
\hline 5 & Yield capacity, kg & 5 & 1.81 & 0.1 & 1.00 \\
\hline 6 & $\mathrm{~N}, \mathrm{gr}$ & 326 & 39.1 & & 43.40 \\
\hline 7 & $\mathrm{P} 2 \mathrm{O} 5, \mathrm{gr}$ & 30 & 21.1 & 1.379 & 10.48 \\
\hline 8 & $\mathrm{~K} 2 \mathrm{O}$, gr & 170 & 50.3 & 1.936 & 27.05 \\
\hline 9 & $\mathrm{~S}, \mathrm{gr}$ & 20 & & 0.244 & 3.22 \\
\hline 10 & $\mathrm{Ca}, \mathrm{gr}$ & 70 & & 0.348 & 8.74 \\
\hline 11 & $\mathrm{Mg}, \mathrm{gr}$ & 39 & & 0.226 & 5.03 \\
\hline
\end{tabular}




\begin{tabular}{|l|l|l|l|l|l|}
\hline 12 & $\mathrm{Cu}, \mathrm{gr}$ & 0.109 & & 0.005 & 0.036 \\
\hline 13 & Mn, gr & 0.653 & & 0.0028 & 0.079 \\
\hline 14 & Zn, gr & 0.261 & & 0.00201 & 0.036 \\
\hline 15 & B, gr & 0.109 & & & 0.022 \\
\hline 16 & Fe, gr & 1.305 & & 0.0097 & 0.18 \\
\hline 17 & Mo, gr & 0.02 & & 0.000099 & 0.0025 \\
\hline 18 & Co, gr & & & 0.0000312 & 0.00031 \\
\hline
\end{tabular}

The columns numbered [31], [32], [33] refer to (Adamenko and Kostyushko, n.d.), (Isupova, 2013), (Chto soderzhitsya v soe?, 2011) respectively.

Table 11. Tomatoes. Biochemical composition of fruits, yield capacity and need in nutrients

\begin{tabular}{|c|c|c|c|c|c|c|c|}
\hline \multirow[b]{2}{*}{ \# } & \multirow[b]{2}{*}{ Indicator } & \multicolumn{5}{|l|}{ Source } & \multirow{2}{*}{$\begin{array}{l}\text { Average } \\
\text { value of } \\
\text { indicator, } \\
\mathrm{gr} / \mathrm{kg} \text { of } \\
\text { yield }\end{array}$} \\
\hline & & {$[34]$} & {$[35]$} & {$[1]$} & {$[1]$} & {$[36]$} & \\
\hline 1 & Protein, gr & 0.6 & & & & & 6.00 \\
\hline 2 & Fats, gr & 0.2 & & & & & 2.00 \\
\hline 3 & Carbohydrates, gr & 4.2 & & & & & 42.00 \\
\hline 4 & Dietary fibers, gr & 0.8 & & & & & 8.00 \\
\hline 5 & Yield capacity, kg & 0.1 & 10000 & 40 & 40 & 3250 & 1.00 \\
\hline 6 & $\mathrm{~N}, \mathrm{gr}$ & & 31500 & 110 & 103 & 11.5 & 2.12 \\
\hline 7 & $\mathrm{P} 2 \mathrm{O} 5, \mathrm{gr}$ & 0.059 & 10500 & 11 & 7 & 4 & 0.42 \\
\hline 8 & $\mathrm{~K} 2 \mathrm{O}$, gr & 0.349 & 42500 & 124.5 & 119.5 & 16 & 2.77 \\
\hline 9 & S, gr & 0.012 & & & & & 0.12 \\
\hline 10 & $\mathrm{Ca}, \mathrm{gr}$ & 0.014 & & 92.3 & 94.4 & & 1.60 \\
\hline 11 & Mg, gr & 0.02 & & & & & 0.20 \\
\hline 12 & $\mathrm{Cu}, \mathrm{gr}$ & 0.00011 & & & & & 0.0011 \\
\hline 13 & $\mathrm{Mn}, \mathrm{gr}$ & 0.00014 & & & & & 0.0014 \\
\hline 14 & $\mathrm{Zn}, \mathrm{gr}$ & 0.0002 & & & & & 0.0020 \\
\hline 15 & $\mathrm{~B}, \mathrm{gr}$ & 0.000115 & & & & & 0.0012 \\
\hline
\end{tabular}




\begin{tabular}{|l|l|l|l|l|l|l|l|}
16 & Fe, gr & 0.0009 & & & & 0.0090 \\
\hline 17 & Mo, gr & 0.000007 & & & & & 0.00007 \\
\hline 18 & Co, gr & 0.000006 & & & & & 0.00006 \\
\hline
\end{tabular}

The columns numbered [1], [34], [35], [36] refer to (Vyraschivanie rasteniy..., 2015), (Yadrov, 2009d), (Osnovnoe vnesenie udobreniy, n.d.), (Podkormka pomidorov, n.d.) respectively.

Table 12. Share of undigested fiber.

\begin{tabular}{|c|c|c|c|}
\hline Crop & $\begin{array}{l}\text { Carbohydrates, } \\
\mathrm{gr} / \mathrm{kg}\end{array}$ & Fiber, gr/kg & $\begin{array}{l}\text { Share of fiber } \\
\text { of } \\
\text { carbohydrate } \\
\text { weight, \% }\end{array}$ \\
\hline Cabbage & 53.00 & 23.00 & $43 \%$ \\
\hline Potato & 163.00 & 16.00 & $10 \%$ \\
\hline Bulb onion & 87.60 & 23.50 & $27 \%$ \\
\hline Carrot & 83.90 & 18.00 & $21 \%$ \\
\hline Cucumber & 19.00 & 7.00 & $37 \%$ \\
\hline Wheat & 667.00 & 117.50 & $18 \%$ \\
\hline Beetroot & 88.00 & 25.00 & $28 \%$ \\
\hline Tomatoes & 42.00 & 8.00 & $19 \%$ \\
\hline \multicolumn{3}{|c|}{ Average value of fiber share } & $25 \%$ \\
\hline
\end{tabular}


Table 13. Biochemical composition of fruits with due regard to fiber

\begin{tabular}{|c|l|l|l|l|}
\hline \multirow{2}{*}{ Crop } & \multicolumn{2}{|l|}{ Biochemical composition of fruits } & \multirow{2}{*}{\begin{tabular}{l} 
Dry weight \\
Protein, \\
\cline { 2 - 4 }
\end{tabular}} & gr/kg \\
& & Fats, gr/kg & $\begin{array}{l}\text { (with } 1.25 \\
\text { coefficient), } \\
\text { gr/kg }\end{array}$ & $\begin{array}{l}\text { gr } \\
\text { groteinds+Carbohydrates) }\end{array}$ \\
\hline Cabbage & 14.27 & 1.50 & 66.25 & 82.02 \\
\hline Potato & 19.67 & 3.00 & 203.75 & 226.42 \\
\hline Bulb onion & 12.50 & 1.67 & 109.50 & 123.67 \\
\hline Carrot & 11.15 & 1.00 & 104.88 & 117.03 \\
\hline Cucumber & 7.00 & 1.00 & 23.75 & 31.75 \\
\hline Wheat & 121.50 & 21.00 & 833.75 & 976.25 \\
\hline Colza & 245.00 & 425.00 & 75.00 & 745.00 \\
\hline Beetroot & 15.00 & 1.00 & 110.00 & 126.00 \\
\hline Soybean & 350.00 & 170.00 & 212.50 & 732.50 \\
\hline Tomatoes & 6.00 & 2.00 & 52.50 & 60.50 \\
\hline
\end{tabular}

Table 14. Overall protein content in plants

\begin{tabular}{|c|l|l|l|l|}
\hline Crop & \multicolumn{1}{|c|}{$\begin{array}{c}\text { Need in } \\
\text { nitrogen, } \\
\text { gr/kg }\end{array}$} & $\begin{array}{c}\text { Protein content in } \\
\text { all plant weight, } \\
\text { gr/kg of fruits }\end{array}$ & $\begin{array}{c}\text { Protein } \\
\text { content in } \\
\text { fruits, gr/kg } \\
\text { of fruits }\end{array}$ & $\begin{array}{r}\text { Protein content } \\
\text { in fruit-free } \\
\text { plant weight, } \\
\mathrm{gr} / \mathrm{kg}\end{array}$ \\
\hline Cabbage & 3.65 & 22.79 & 14.27 & 8.52 \\
\hline Potato & 5.13 & 32.04 & 19.67 & 12.38 \\
\hline Bulb onion & 4.40 & 27.50 & 12.50 & 15.00 \\
\hline Carrot & 3.20 & 20.00 & 11.15 & 8.85 \\
\hline Cucumber & 3.04 & 18.98 & 7.00 & 11.98 \\
\hline Wheat & 30.28 & 189.22 & 121.50 & 67.72 \\
\hline Colza & 50.50 & 315.63 & 245.00 & 70.63 \\
\hline Beetroot & 3.35 & 20.94 & 15.00 & 5.94 \\
\hline Soybean & $65.20 *$ & 407.50 & 350.00 & $57.50 *$ \\
\hline Tomatoes & 2.12 & 13.25 & 6.00 & 7.25 \\
\hline
\end{tabular}


Table 15. Chemical composition of feedstuff herbage (Himicheskiy sostav..., n.d.).

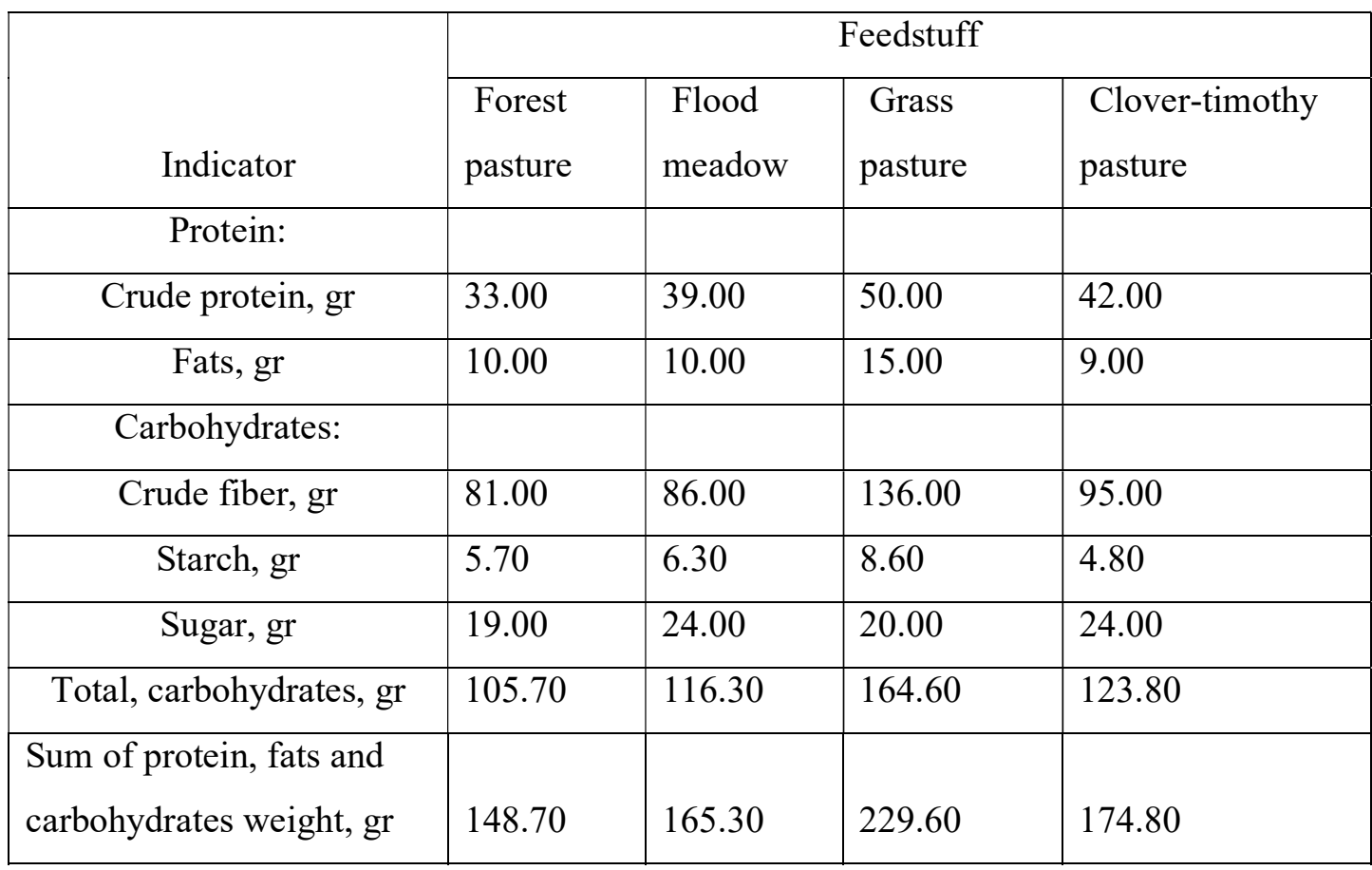

Table 16. Analysis of biochemical composition of fruits in given crops, except wheat, colza, soybean (biochemical composition of fruits)

\begin{tabular}{|c|c|c|c|c|c|c|c|c|}
\hline \multirow[b]{2}{*}{ Crop } & \multicolumn{3}{|c|}{$\begin{array}{c}\text { Biochemical composition of } \\
\text { fruits }\end{array}$} & \multirow{2}{*}{$\begin{array}{c}\text { Dry } \\
\text { weight } \\
\text { (Protein } \\
\text { +Fats+ } \\
\text { Carboh } \\
\text { ydrates) } \\
\text {, gr }\end{array}$} & \multirow[b]{2}{*}{$\begin{array}{l}\text { Protein } \\
\text { content } \\
\text { in the } \\
\text { initial } \\
\text { weight }\end{array}$} & \multicolumn{3}{|c|}{ Dry weight composition } \\
\hline & $\begin{array}{l}\text { Protein, } \\
\mathrm{gr} / \mathrm{kg}\end{array}$ & $\begin{array}{l}\text { Fats, } \\
\text { gr/kg }\end{array}$ & $\begin{array}{c}\text { Carbohydrat } \\
\text { es } \\
\text { (with } 1.25 \\
\text { coefficient), } \\
\text { gr/kg }\end{array}$ & & & $\begin{array}{c}\text { Protein, } \\
\%\end{array}$ & $\begin{array}{c}\text { Fats, } \\
\%\end{array}$ & $\begin{array}{l}\text { Carbohy } \\
\text { drates, \% }\end{array}$ \\
\hline Cabbage & 14.27 & 1.50 & 66.25 & 82.02 & $1 \%$ & $17.39 \%$ & $\begin{array}{l}1.83 \\
\%\end{array}$ & $80.78 \%$ \\
\hline Potato & 19.67 & 3.00 & 203.75 & 226.42 & $2 \%$ & $8.69 \%$ & $\begin{array}{l}1.32 \\
\%\end{array}$ & $89.99 \%$ \\
\hline Bulb onion & 12.50 & 1.67 & 109.50 & 123.67 & $1 \%$ & $10.11 \%$ & $\begin{array}{l}1.35 \\
\%\end{array}$ & $88.54 \%$ \\
\hline Carrot & 11.15 & 1.00 & 104.88 & 117.03 & $1 \%$ & $9.53 \%$ & $\begin{array}{l}0.85 \\
\%\end{array}$ & $89.62 \%$ \\
\hline Cucumber & & & & & $1 \%$ & $22.05 \%$ & 3.15 & $74.80 \%$ \\
\hline
\end{tabular}




\begin{tabular}{|l|l|l|l|l|l|l|l|l|} 
& 7.00 & 1.00 & 23.75 & 31.75 & & & $\%$ & \\
\hline Beetroot & 15.00 & 1.00 & 110.00 & 126.00 & $2 \%$ & $11.90 \%$ & $\%$ & $87.30 \%$ \\
\hline Tomatoes & 6.00 & 2.00 & 52.50 & 60.50 & $1 \%$ & $9.92 \%$ & $\%$ & $86.78 \%$ \\
\hline
\end{tabular}

Table 17. Comparison of biochemical composition of fruits and feedstuff herbage.

\begin{tabular}{|c|c|c|}
\hline \multirow[b]{2}{*}{ Indicator } & \multicolumn{2}{|c|}{ Content, \% } \\
\hline & Fruits, figure 2 & Feedstuff herbage, figure 1 \\
\hline Protein & $10.18 \%$ & $22.74 \%$ \\
\hline Fats & $1.31 \%$ & $6.15 \%$ \\
\hline Carbohydrates & $88.51 \%$ & $71.11 \%$ \\
\hline & $100.00 \%$ & $100.00 \%$ \\
\hline
\end{tabular}

Table 18. Biochemical composition of fruit-free plant mass

\begin{tabular}{|c|c|c|c|c|}
\hline \multirow[b]{2}{*}{ \# } & \multirow[b]{2}{*}{ Crop } & \multicolumn{3}{|c|}{ Content in fruit-free plant weight } \\
\hline & & $\begin{array}{l}\text { Protein, gr/kg of } \\
\text { yield (Table 13) }\end{array}$ & $\begin{array}{l}\text { Fats, } \mathrm{gr} / \mathrm{kg} \text { of } \\
\text { yield }\end{array}$ & $\begin{array}{l}\text { Carbohydrates, } \\
\text { gr/kg of yield }\end{array}$ \\
\hline 1 & Cabbage & 8.52 & 1.10 & 74.07 \\
\hline 2 & Potato & 12.38 & 1.59 & 107.61 \\
\hline 3 & Bulb onion & 15.00 & 1.93 & 130.42 \\
\hline 4 & Carrot & 8.85 & 1.14 & 76.95 \\
\hline 5 & Cucumber & 11.98 & 1.54 & 104.14 \\
\hline 6 & Wheat & 67.72 & 8.71 & 588.78 \\
\hline 7 & Colza & 70.63 & 9.09 & 614.05 \\
\hline 8 & Beetroot & & & \\
\hline
\end{tabular}




\begin{tabular}{|l|l|l|l|l|} 
& & 5.94 & 0.76 & 51.62 \\
\hline 9 & Soybean & 57.50 & 7.40 & 499.93 \\
\hline 10 & Tomatoes & 7.25 & 0.93 & 63.02 \\
\hline
\end{tabular}

Table 19. General biochemical composition of plants based on Table 12 and Table 17.

Energy value equivalent.

\begin{tabular}{|c|c|c|c|c|c|}
\hline \multirow[b]{2}{*}{$\#$} & \multirow[b]{2}{*}{ Crop } & \multicolumn{3}{|c|}{ Content in all plant weight } & \multirow[b]{2}{*}{$\begin{array}{l}\text { Energy value } \\
\text { equivalent, } \\
\mathrm{P}+2.268 * \mathrm{~F}+\mathrm{C}\end{array}$} \\
\hline & & $\begin{array}{c}\text { Protein, } \\
\text { gr } / \mathrm{kg} \text { of } \\
\text { yield }\end{array}$ & $\begin{array}{c}\text { Fats, } \\
\text { gr/kg of } \\
\text { yield }\end{array}$ & $\begin{array}{c}\text { Carbohydrates, } \\
\text { gr/kg of yield }\end{array}$ & \\
\hline 1 & Cabbage & 22.79 & 2.60 & 140.32 & 168.99 \\
\hline 2 & Potato & 32.04 & 4.59 & 311.36 & 353.82 \\
\hline 3 & Bulb onion & 27.50 & 3.60 & 239.92 & 275.58 \\
\hline 4 & Carrot & 20.00 & 2.14 & 181.82 & 206.67 \\
\hline 5 & Cucumber & 18.98 & 2.54 & 127.89 & 152.63 \\
\hline 6 & Wheat & 189.22 & 29.71 & $1,422.53$ & $1,679.14$ \\
\hline 7 & Colza & 315.63 & 434.09 & 689.05 & $1,989.19$ \\
\hline 8 & Beetroot & 20.94 & 1.76 & 161.62 & 186.56 \\
\hline 9 & Soybean & 407.50 & 177.40 & 712.43 & $1,522.28$ \\
\hline 10 & Tomatoes & 13.25 & 2.93 & 115.52 & 135.41 \\
\hline
\end{tabular}


Table 20. Deviations of colza and soybean from the dependence of protein, fat and carbohydrate relative weights on EVE

\begin{tabular}{|c|l|c|l|c|l|l|l|}
\hline$\#$ & \multicolumn{1}{|c|}{ Crop } & $\begin{array}{c}\text { Plant } \\
\text { EVE }\end{array}$ & $\begin{array}{c}\text { Protein } \\
\text { deviation, gr }\end{array}$ & $\begin{array}{c}\text { Fat } \\
\text { deviation, } \\
\text { gr }\end{array}$ & $\begin{array}{c}\text { Carbohydrat } \\
\text { e deviation, } \\
\text { gr }\end{array}$ & $\begin{array}{c}\text { Devof } \\
\text { n EVE }\end{array}$ & $\begin{array}{c}\text { deviation } \\
\text { from plant } \\
\text { EVE }\end{array}$ \\
\hline 1 & Colza & $1,989.19$ & 113.13 & 407.83 & $-1,038.16$. & -0.07. & $-0.0038 \%$ \\
\hline 2 & Soybean & $1,522.28$ & 252.53 & 157.31 & -609.36. & -0.06. & $-0.0038 \%$ \\
\hline
\end{tabular}

Table 21. Energy value of plants per $1 \mathrm{~kg}$ of relative dry weight with regard to the dependences in Figure 3.

\begin{tabular}{|l|l|l|l|l|l|l|}
\hline Protein, gr & Fats, gr & $\begin{array}{c}\text { Carbohydrates, } \\
\text { gr }\end{array}$ & $\begin{array}{c}\text { Dry weight, } \\
\text { gr }\end{array}$ & EVE & \multicolumn{2}{|c|}{ Energy value } \\
\cline { 6 - 7 } & & & & $\mathrm{kcal} / \mathrm{kg}$ & $\mathrm{kJ} / \mathrm{kg}$ \\
\hline 101.80 & 13.20 & 868.30 & 983.30 & $1,000.0$ & $4,169.79$ & $17,458.08$ \\
\hline
\end{tabular}

Table 22. Plant's need in $\mathrm{P} 2 \mathrm{O} 5$

\begin{tabular}{|c|l|l|l|}
\hline$\#$ & Crop & $\begin{array}{l}\text { Energy value equivalent, } \mathrm{P}+ \\
2.268^{*} \mathrm{~F}+\mathrm{C}\end{array}$ & $\begin{array}{l}\text { Average need in P2O5, } \\
\text { gr/kg of yield }\end{array}$ \\
\hline 1 & Cabbage & 168.99 & 0.68 \\
\hline 2 & Potato & 353.82 & 1.54 \\
\hline 3 & Bulb onion & 275.58 & 1.03 \\
\hline 4 & Carrot & 206.67 & 1.06 \\
\hline 5 & Cucumber & 152.63 & 2.10 \\
\hline 6 & Wheat & 1.679 .14 & 9.54 \\
\hline 7 & Colza & 1.989 .19 & 23.75 \\
\hline 8 & Beetroot & 186.56 & 1.08 \\
\hline 9 & Soybean & 1.522 .28 & 10.48 \\
\hline 10 & Tomatoes & 135.41 & 0.42 \\
\hline
\end{tabular}


Table 23. Plant's need in K2O.

\begin{tabular}{|c|c|c|c|}
\hline \# & Crop & $\begin{array}{l}\text { Energy value } \\
\text { equivalent, } \mathrm{P}+ \\
2.268^{*} \mathrm{~F}+\mathrm{C}\end{array}$ & $\begin{array}{l}\text { Average } \\
\text { need in } \\
\mathrm{K} 2 \mathrm{O}, \mathrm{gr} / \mathrm{kg} \\
\text { of yield }\end{array}$ \\
\hline 1 & Cabbage & 168.99 & 3.33 \\
\hline 2 & Potato & 353.82 & 7.74 \\
\hline 3 & Bulb onion & 275.58 & 1.96 \\
\hline 4 & Carrot & 206.67 & 3.89 \\
\hline 5 & Cucumber & 152.63 & 4.02 \\
\hline 6 & Wheat & $1,679.14$ & 14.83 \\
\hline 7 & Colza & $1,989.19$ & 48.75 \\
\hline 8 & Beetroot & 186.56 & 4.32 \\
\hline 9 & Soybean & $1,522.28$ & 27.05 \\
\hline 10 & Tomatoes & 135.41 & 2.77 \\
\hline
\end{tabular}

Table 24. Content of sulfur (S) in fruits

\begin{tabular}{|c|c|l|l|}
\hline$\#$ & Crop & Fats, gr/kg of yield & $\begin{array}{l}\text { Average S } \\
\text { content in fruits, } \\
\text { gr/kg of yield }\end{array}$ \\
\hline 1 & Cabbage & 1.50 & 0.37 \\
\hline 2 & Potato & 3.00 & 0.32 \\
\hline 3 & Bulb onion & 1.67 & 0.65 \\
\hline
\end{tabular}




\begin{tabular}{|c|c|l|l|}
\hline 4 & Carrot & 1.00 & 0.06 \\
\hline 5 & Cucumber & 1.00 & \\
\hline 6 & Wheat & 21.00 & 2.38 \\
\hline 7 & Colza & 425.00 & 20.00 \\
\hline 8 & Beetroot & 1.00 & 0.07 \\
\hline 9 & Soybean & 170.00 & 3.22 \\
\hline 10 & Tomatoes & 2.00 & 0.12 \\
\hline
\end{tabular}

Table 25. Content of calcium $(\mathrm{Ca})$ in fruits

\begin{tabular}{|c|l|l|l|}
\hline$\#$ & Crop & $\begin{array}{l}\text { Fats, gr/kg of } \\
\text { yield }\end{array}$ & $\begin{array}{l}\text { Average Ca content in } \\
\text { fruits, gr/kg of yield }\end{array}$ \\
\hline 1 & Cabbage & 1.50 & 1.83 \\
\hline 2 & Potato & 3.00 & 1.31 \\
\hline 3 & Bulb onion & 1.67 & 0.32 \\
\hline 4 & Carrot & 1.00 & 0.40 \\
\hline 5 & Cucumber & 1.00 & 1.14 \\
\hline 6 & Wheat & 21.00 & 1.14 \\
\hline 7 & Colza & 425.00 & 60.00 \\
\hline 8 & Beetroot & 1.00 & 0.72 \\
\hline 9 & Soybean & 170.00 & 8.74 \\
\hline 10 & Tomatoes & 2.00 & 1.60 \\
\hline
\end{tabular}

Table 26. Content of magnesium $(\mathrm{Mg})$ in fruits

\begin{tabular}{|c|c|c|c|c|c|}
\hline \multirow[b]{2}{*}{ \# } & \multirow[b]{2}{*}{ Crop } & \multicolumn{2}{|c|}{$\begin{array}{c}\text { Biochemical composition of } \\
\text { fruits }\end{array}$} & \multirow{2}{*}{$\begin{array}{l}\text { Sum of protein } \\
\text { and fat weight, } \\
\text { gr } / \mathrm{kg} \text { of yield }\end{array}$} & \multirow{2}{*}{$\begin{array}{l}\text { Average } \mathrm{Mg} \\
\text { content in fruits, } \\
\text { gr/kg of yield }\end{array}$} \\
\hline & & $\begin{array}{l}\text { Protein, } \mathrm{gr} / \mathrm{kg} \text { of } \\
\text { yield }\end{array}$ & $\begin{array}{l}\text { Fats, } \mathrm{gr} / \mathrm{kg} \text { of } \\
\text { yield }\end{array}$ & & \\
\hline 1 & Cabbage & 14.27 & 1.50 & 15.77 & 0.143 \\
\hline 2 & Potato & 19.67 & 3.00 & 22.67 & 0.395 \\
\hline 3 & Bulb onion & 12.50 & 1.67 & 14.17 & 0.144 \\
\hline 4 & Carrot & 11.15 & 1.00 & 12.15 & 0.240 \\
\hline 5 & Cucumber & 7.00 & 1.00 & 8.00 & 0.355 \\
\hline 6 & Wheat & 121.50 & 21.00 & 142.50 & 1.97 \\
\hline
\end{tabular}




\begin{tabular}{|l|l|l|l|l|l|}
7 & Colza & 245.00 & 425.00 & 670.00 & 10.00 \\
\hline 8 & Beetroot & 15.00 & 1.00 & 16.00 & 0.220 \\
\hline 9 & Soybean & 350.00 & 170.00 & 520.00 & 5.03 \\
\hline 10 & Tomatoes & 6.00 & 2.00 & 8.00 & 0.200 \\
\hline
\end{tabular}

Table 27. Content of copper $(\mathrm{Cu})$ in fruits

\begin{tabular}{|c|c|c|c|c|c|}
\hline \multirow[b]{2}{*}{ \# } & \multirow[b]{2}{*}{ Crop } & \multicolumn{2}{|c|}{$\begin{array}{c}\text { Biochemical composition of } \\
\text { fruits }\end{array}$} & \multirow[b]{2}{*}{$\begin{array}{l}\text { Sum of protein } \\
\text { and fat weight, } \\
\text { gr/kg of yield }\end{array}$} & \multirow{2}{*}{$\begin{array}{l}\text { Average } \mathrm{Cu} \\
\text { content in } \\
\text { fruits, } \mathrm{gr} / \mathrm{kg} \text { of } \\
\text { yield }\end{array}$} \\
\hline & & $\begin{array}{l}\text { Protein, } \\
\text { gr } / \mathrm{kg} \text { of } \\
\text { yield }\end{array}$ & $\begin{array}{l}\text { Fats, } \mathrm{gr} / \mathrm{kg} \text { of } \\
\text { yield }\end{array}$ & & \\
\hline 1 & Cabbage & 14.27 & 1.50 & 15.77 & 0.00047 \\
\hline 2 & Potato & 19.67 & 3.00 & 22.67 & 0.00140 \\
\hline 3 & Bulb onion & 12.50 & 1.67 & 14.17 & 0.00062 \\
\hline 4 & Carrot & 11.15 & 1.00 & 12.15 & 0.00063 \\
\hline 5 & Cucumber & 7.00 & 1.00 & 8.00 & 0.00100 \\
\hline 6 & Wheat & 121.50 & 21.00 & 142.50 & 0.00747 \\
\hline 7 & Colza & 245.00 & 425.00 & 670.00 & 0.04000 \\
\hline 8 & Beetroot & 15.00 & 1.00 & 16.00 & 0.00140 \\
\hline 9 & Soybean & 350.00 & 170.00 & 520.00 & 0.03590 \\
\hline 10 & Tomatoes & 6.00 & 2.00 & 8.00 & 0.00110 \\
\hline
\end{tabular}

Table 28. Content of manganese (Mn) in fruits

\begin{tabular}{|c|c|l|l|}
\hline$\#$ & Crop & Fats, gr/kg of yield & $\begin{array}{l}\text { Average Mn content } \\
\text { in fruits, gr/kg of yield }\end{array}$ \\
\hline 1 & Cabbage & 1.50 & 0.00177 \\
\hline 2 & Potato & 3.00 & 0.00170 \\
\hline 3 & Bulb onion & 1.67 & 0.00153 \\
\hline 4 & Carrot & 1.00 & 0.00172 \\
\hline 5 & Cucumber & 1.00 & 0.00180 \\
\hline 6 & Wheat & 21.00 & 0.06550 \\
\hline 7 & Colza & 425.00 & 0.57500 \\
\hline 8 & Beetroot & 1.00 & 0.00660 \\
\hline
\end{tabular}




\begin{tabular}{|c|c|l|l|}
\hline 9 & Soybean & 170.00 & 0.07930 \\
\hline 10 & Tomatoes & 2.00 & 0.00140 \\
\hline
\end{tabular}

Table 29. Content of zinc ( $\mathrm{Zn})$ in fruits

\begin{tabular}{|c|c|l|l|}
\hline$\#$ & Crop & Fats, gr/kg of yield & $\begin{array}{l}\text { Average Zn content in } \\
\text { fruits, gr/kg of yield }\end{array}$ \\
\hline 1 & Cabbage & 1.50 & 0.00260 \\
\hline 2 & Potato & 3.00 & 0.00360 \\
\hline 3 & Bulb onion & 1.67 & 0.00407 \\
\hline 4 & Carrot & 1.00 & 0.00320 \\
\hline 5 & Cucumber & 1.00 & 0.00215 \\
\hline 6 & Wheat & 21.00 & 0.04394 \\
\hline 7 & Colza & 425.00 & 0.15000 \\
\hline 8 & Beetroot & 1.00 & 0.00425 \\
\hline 9 & Soybean & 170.00 & 0.03615 \\
\hline 10 & Tomatoes & 2.00 & 0.00200 \\
\hline
\end{tabular}

Table 30. Content of boracium (B) in fruits

\begin{tabular}{|c|c|l|l|}
\hline$\#$ & Crop & Fats, gr/kg of yield & $\begin{array}{l}\text { Average B content in } \\
\text { fruits, gr/kg of yield }\end{array}$ \\
\hline 1 & Cabbage & 1.50 & 0.00200 \\
\hline 2 & Potato & 3.00 & 0.00115 \\
\hline 3 & Bulb onion & 1.67 & 0.00200 \\
\hline 4 & Carrot & 1.00 & 0.00200 \\
\hline 5 & Cucumber & 1.00 & \\
\hline 6 & Wheat & 21.00 & 0.01500 \\
\hline 7 & Colza & 425.00 & 0.08000 \\
\hline 8 & Beetroot & 1.00 & 0.00280 \\
\hline 9 & Soybean & 170.00 & 0.02180 \\
\hline 10 & Tomatoes & 2.00 & 0.00115 \\
\hline
\end{tabular}


Table 31. Content of ferrum (Fe) in fruits

\begin{tabular}{|c|c|c|c|c|c|}
\hline \multirow[b]{2}{*}{ \# } & \multirow[b]{2}{*}{ Crop } & \multicolumn{2}{|c|}{$\begin{array}{l}\text { Biochemical composition of } \\
\text { fruits }\end{array}$} & \multirow{2}{*}{$\begin{array}{l}\text { Sum of } \\
\text { protein and } \\
\text { fat weight, } \\
\text { gr/kg of yield }\end{array}$} & \multirow[b]{2}{*}{$\begin{array}{l}\text { Average Fe } \\
\text { content in fruits, } \\
\text { gr/kg of yield }\end{array}$} \\
\hline & & $\begin{array}{l}\text { Protein, } \\
\mathrm{gr} / \mathrm{kg} \text { of } \\
\text { yield }\end{array}$ & $\begin{array}{l}\text { Fats, } \mathrm{gr} / \mathrm{kg} \text { of } \\
\text { yield }\end{array}$ & & \\
\hline 1 & Cabbage & 14.27 & 1.50 & 15.77 & 0.00557 \\
\hline 2 & Potato & 19.67 & 3.00 & 22.67 & 0.00833 \\
\hline 3 & Bulb onion & 12.50 & 1.67 & 14.17 & 0.00403 \\
\hline 4 & Carrot & 11.15 & 1.00 & 12.15 & 0.00850 \\
\hline 5 & Cucumber & 7.00 & 1.00 & 8.00 & 0.00500 \\
\hline 6 & Wheat & 121.50 & 21.00 & 142.50 & 0.07225 \\
\hline 7 & Colza & 245.00 & 425.00 & 670.00 & 0.36000 \\
\hline 8 & Beetroot & 15.00 & 1.00 & 16.00 & 0.01400 \\
\hline 9 & Soybean & 350.00 & 170.00 & 520.00 & 0.17900 \\
\hline 10 & Tomatoes & 6.00 & 2.00 & 8.00 & 0.00900 \\
\hline
\end{tabular}

Table 32. Content of molybdenum (Mo) in fruits

\begin{tabular}{|c|c|l|l|}
\hline$\#$ & Crop & $\begin{array}{l}\text { Fats, gr/kg } \\
\text { of yield }\end{array}$ & $\begin{array}{l}\text { Average Mo } \\
\text { content in fruits, } \\
\text { gr/kg of yield }\end{array}$ \\
\hline 1 & Cabbage & 1.50 & 0.00010 \\
\hline 2 & Potato & 3.00 & 0.00008 \\
\hline 3 & Bulb onion & 1.67 & 0.00012 \\
\hline 4 & Carrot & 1.00 & 0.00020 \\
\hline 5 & Cucumber & 1.00 & 0.00001 \\
\hline 6 & Wheat & 21.00 & 0.00038 \\
\hline 7 & Colza & 425.00 & 0.00625 \\
\hline 8 & Beetroot & 1.00 & 0.00010 \\
\hline 9 & Soybean & 170.00 & 0.00250 \\
\hline 10 & Tomatoes & 2.00 & 0.00007 \\
\hline
\end{tabular}


Table 33. Plants' need in cobalt (Co)

\begin{tabular}{|c|l|l|l|}
\hline$\#$ & Crop & $\begin{array}{l}\text { Protein, gr/kg of } \\
\text { yield }\end{array}$ & $\begin{array}{l}\text { Average Co } \\
\text { content in fruits, } \\
\text { gr/kg of yield }\end{array}$ \\
\hline 1 & Cabbage & 14.27 & 0.00003 \\
\hline 2 & Potato & 19.67 & 0.00005 \\
\hline 3 & Bulb onion & 12.50 & 0.00005 \\
\hline 4 & Carrot & 11.15 & 0.00002 \\
\hline 5 & Cucumber & 7.00 & 0.00001 \\
\hline 6 & Wheat & 121.50 & 0.00023 \\
\hline 7 & Beetroot & 15.00 & 0.00002 \\
\hline 8 & Soybean & 350.00 & 0.00031 \\
\hline 9 & Tomatoes & 6.00 & 0.00006 \\
\hline
\end{tabular}

\section{Figures}

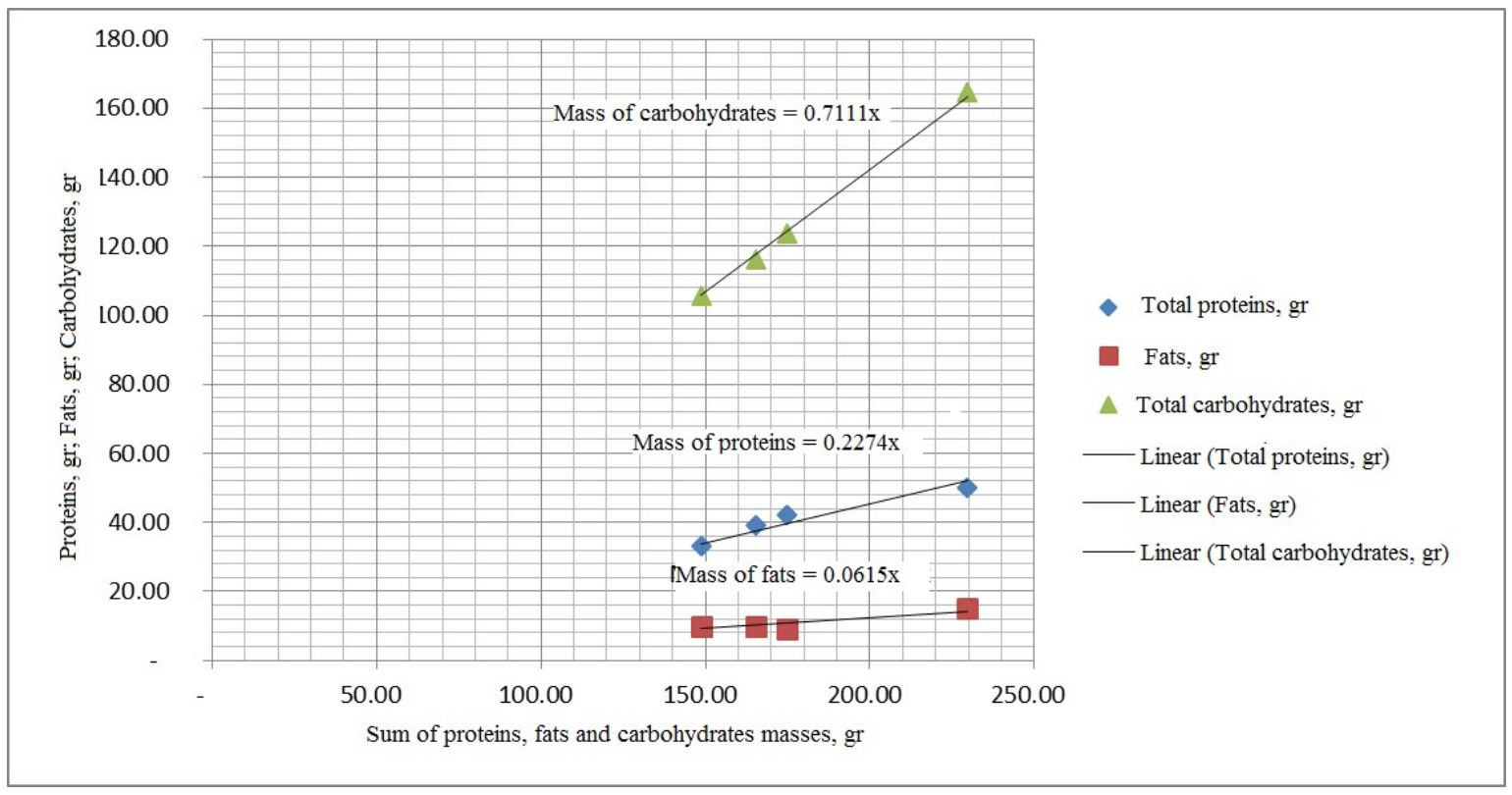

Fig.1. Dependence of protein, fats and carbohydrates weight in feedstuff herbage on their masses sum. 


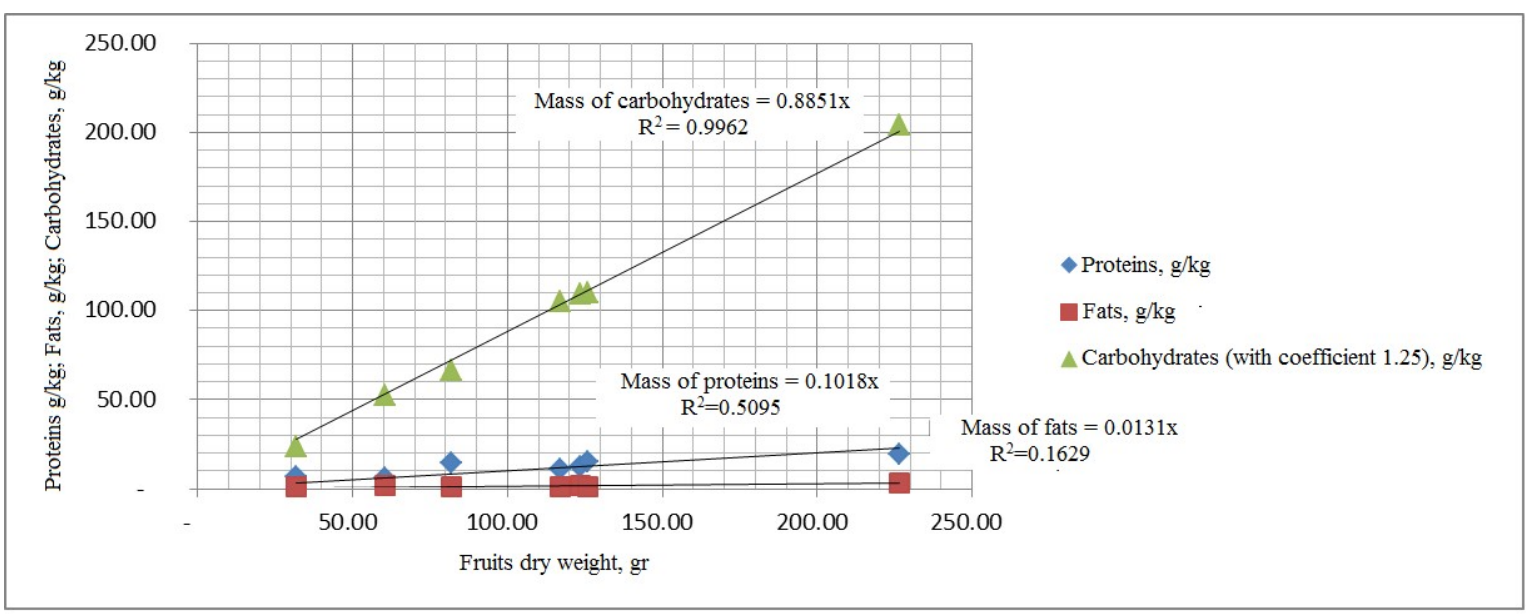

Fig.2. Dependence of protein, fat and carbohydrates weights in fruits on fruits dry masses.

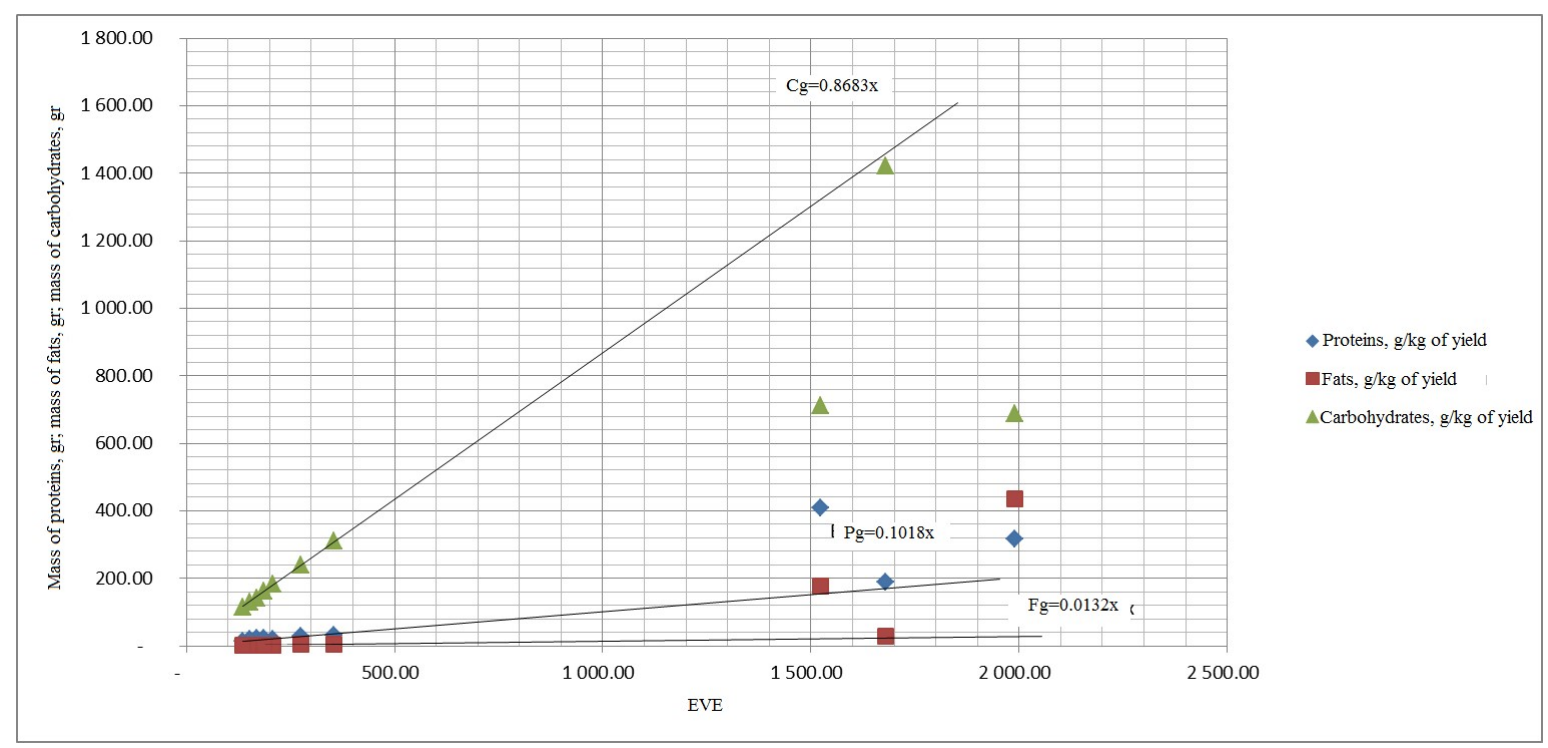

Fig.3. Dependence of protein, fats and carbohydrates weight on EVE. 


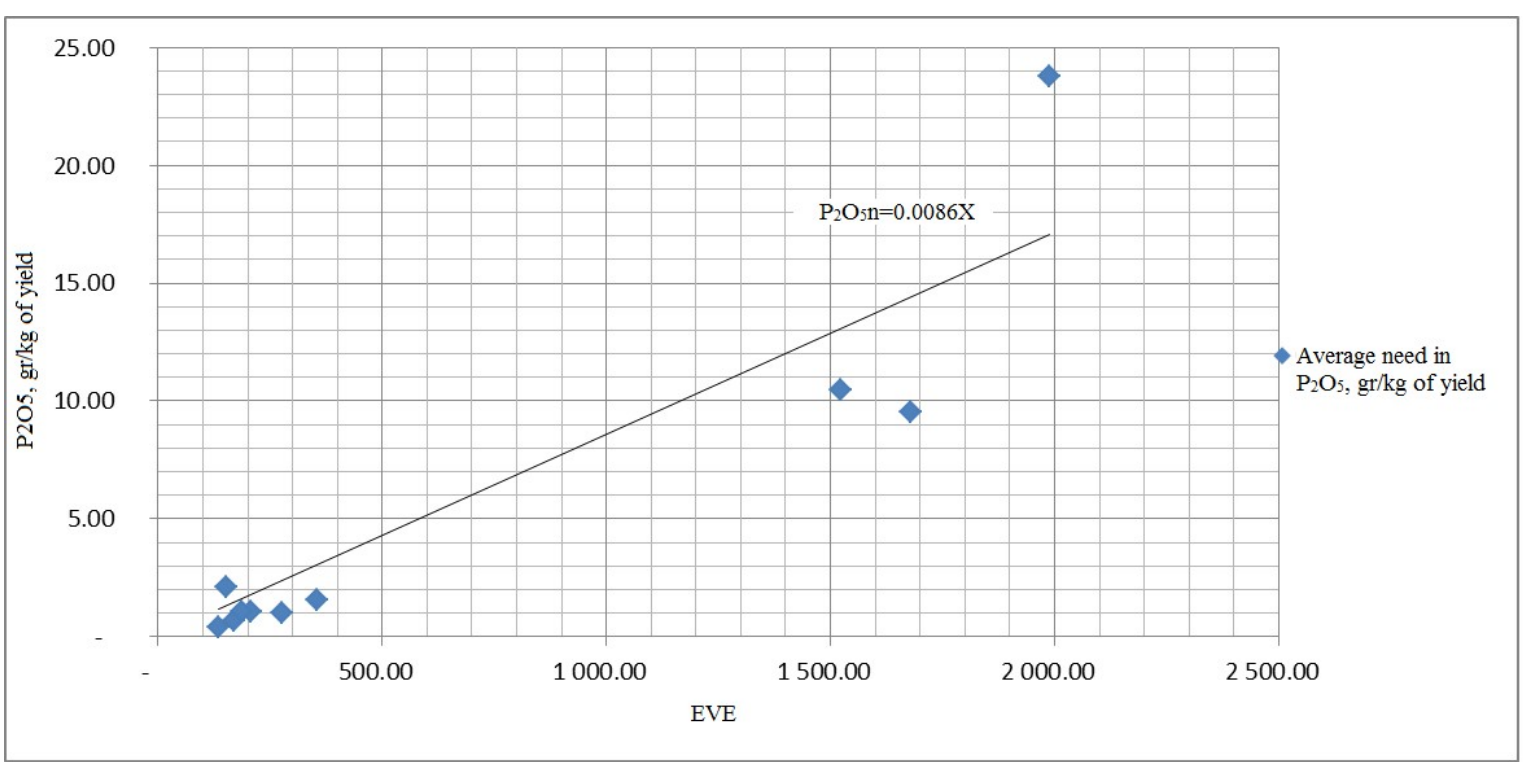

Fig.4. Dependence of need in P2O5 on energy value equivalent. $\mathrm{R}=0.922$, where $\mathrm{R}$ is the coefficient determining the correlation ratio and the reliability of the model.

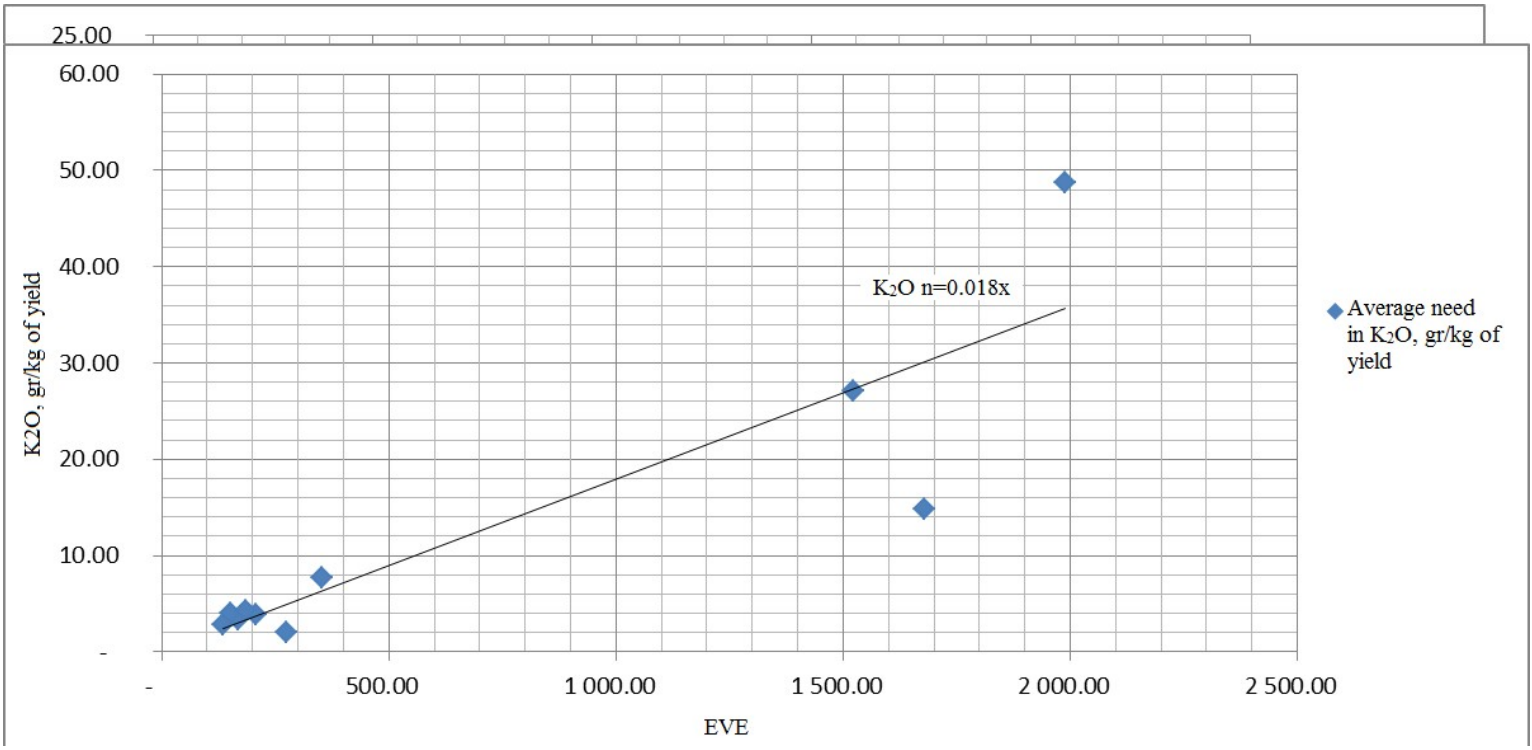

Fig.5. Dependence of need in $\mathrm{K} 2 \mathrm{O}$ on energy value equivalent. $\mathrm{R}=0.892$, where $\mathrm{R}$ is the coefficient determining the correlation ratio and the reliability of the model. 


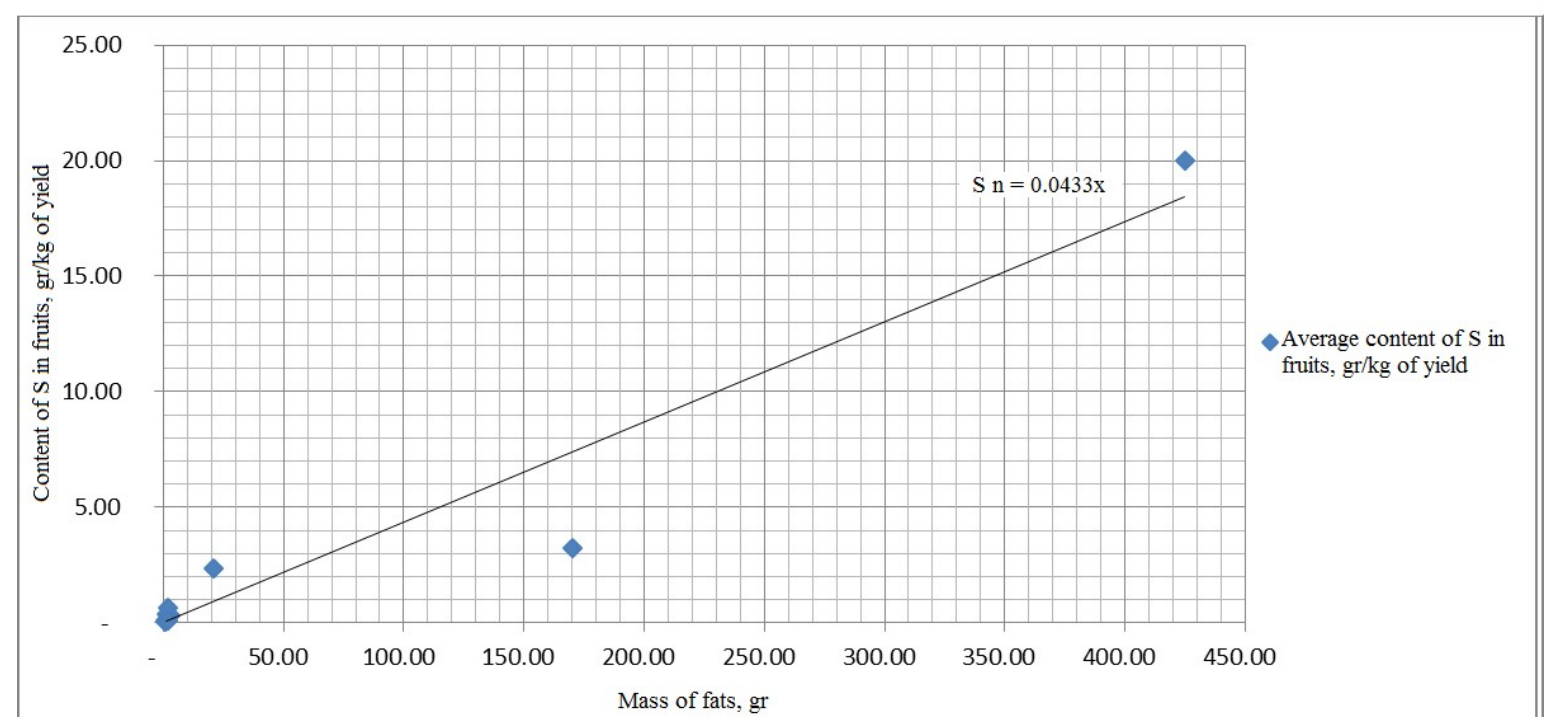

Fig.6. Dependence of sulfur (S) content in fruits on fat weight. $R=0.966$, where $R$ is the correlation determining the correlation ratio and the reliability of the model.

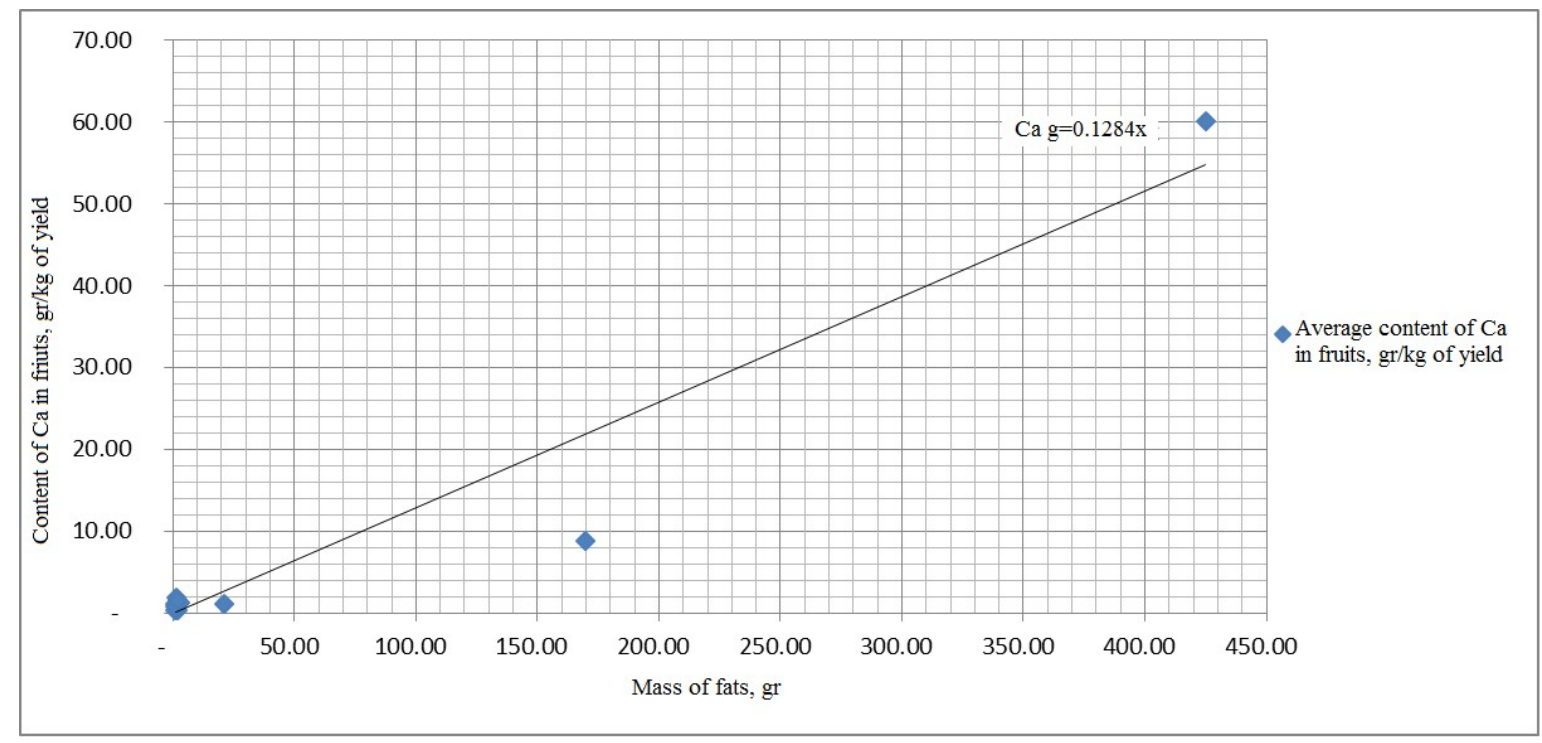

Fig.7. Dependence of calcium $(\mathrm{Ca})$ content in fruits on fat weight. $\mathrm{R}=0.966$, where $\mathrm{R}$ is the coefficient determining the correlation ratio and the reliability of the model. 


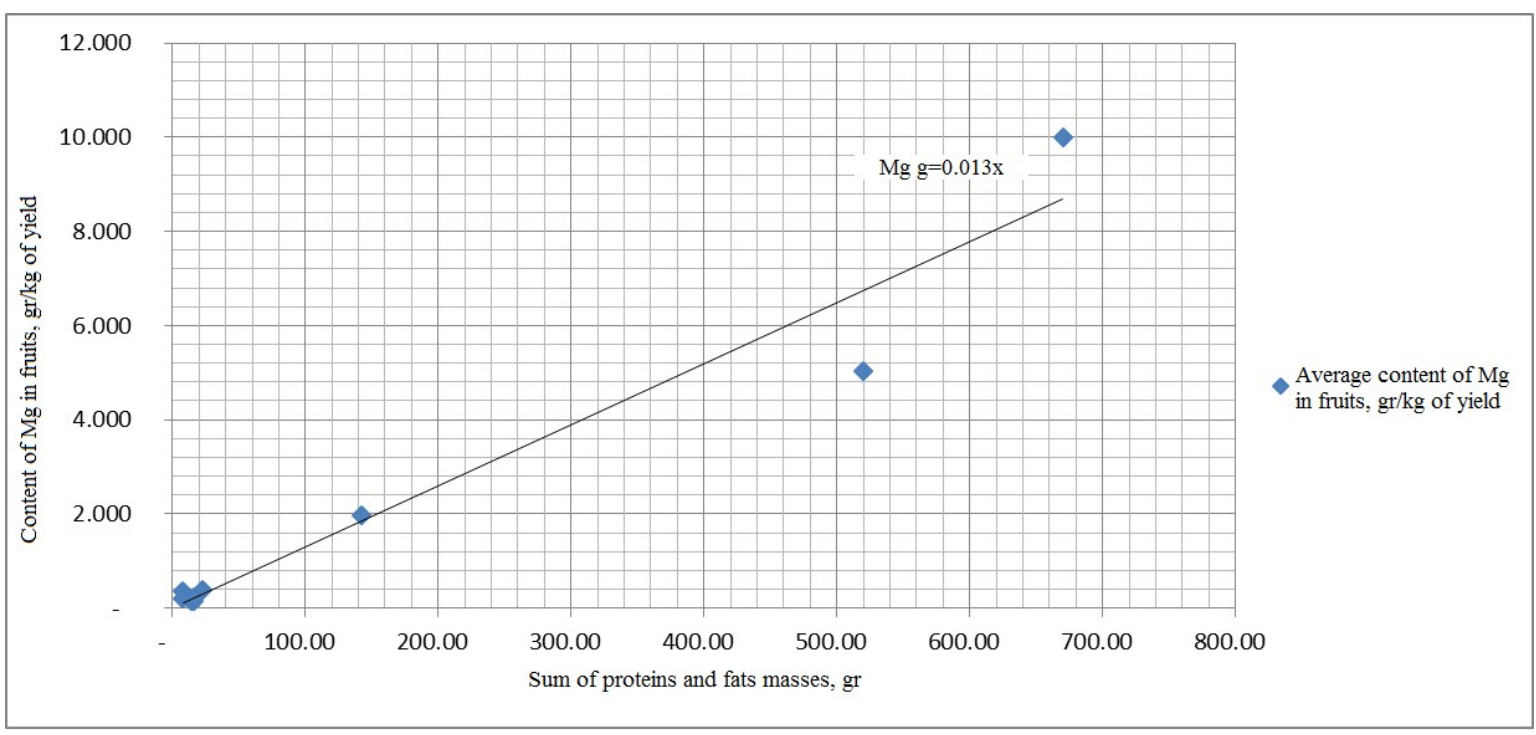

Fig.8. Dependence of magnesium $(\mathrm{Mg})$ content in fruits on the sum of protein and fat weight. $\mathrm{R}=0.975$, where $\mathrm{R}$ is the coefficient determining the correlation ratio and the reliability of the model.

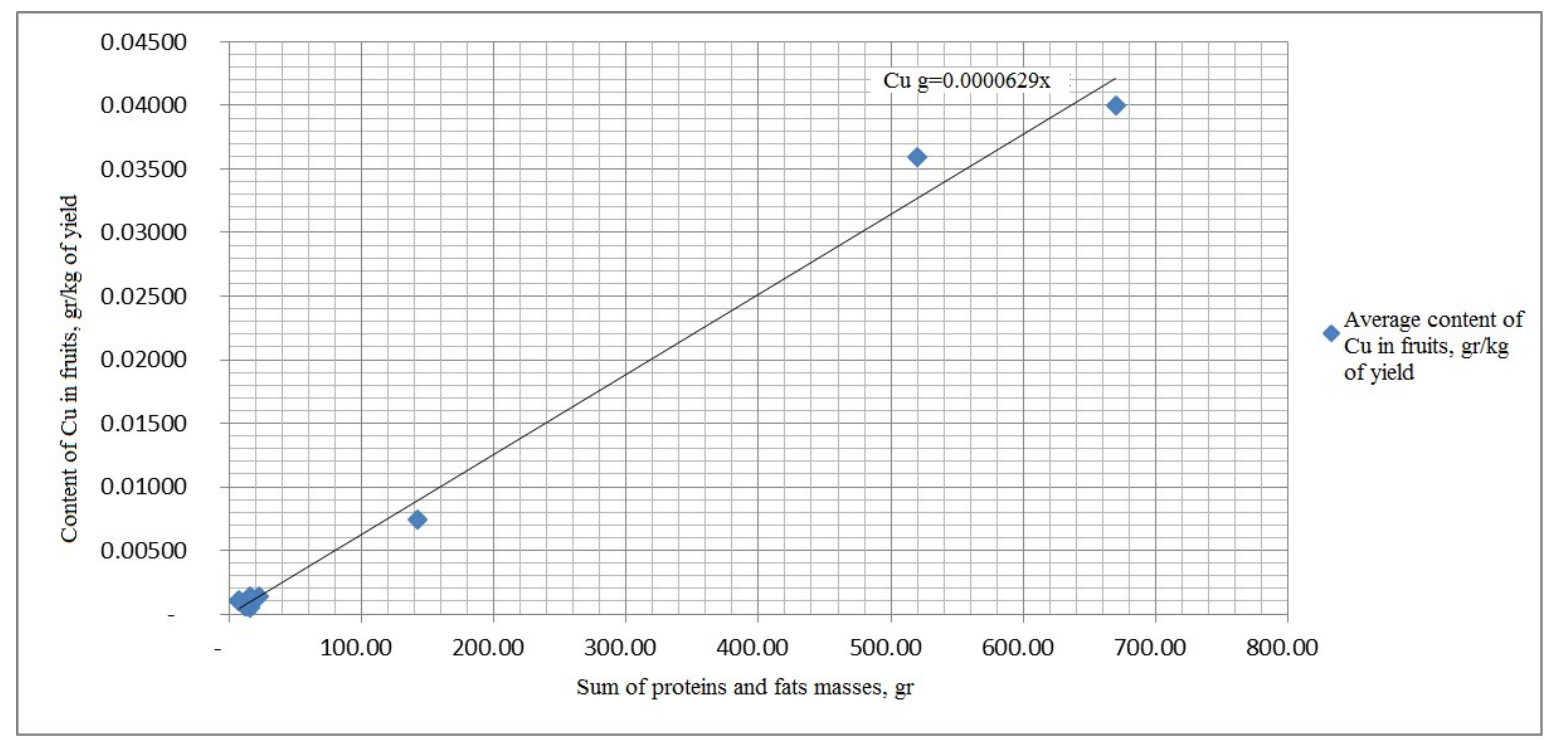

Fig.9. Dependence of copper $(\mathrm{Cu})$ content in fruits on the sum of protein and fat weight. $\mathrm{R}=$ 0.996, where $\mathrm{R}$ is the coefficient determining the correlation ratio and the reliability of the model. 


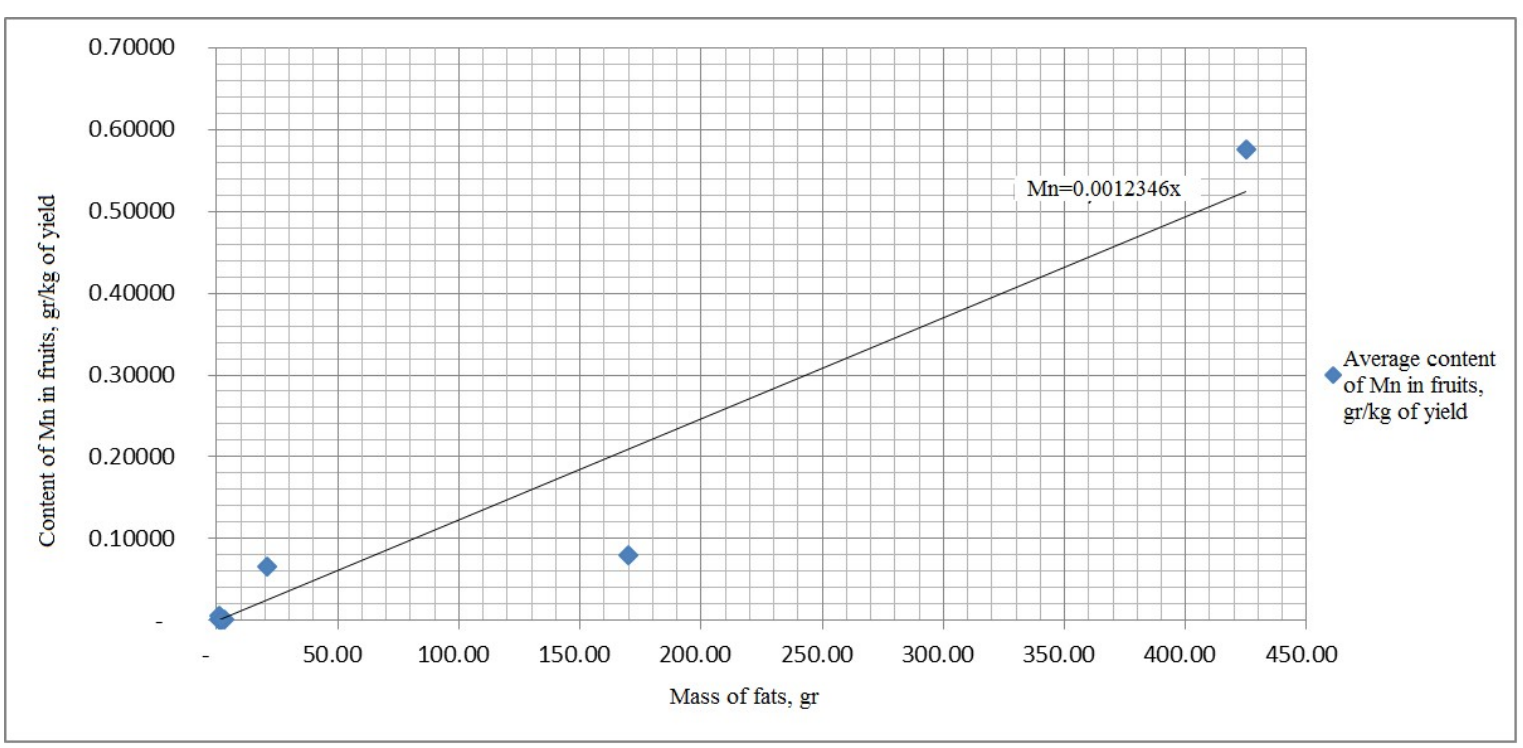

Fig.10. Dependence of manganese $(\mathrm{Mn})$ content in fruits on fat weight. $R=0.963$, where $R$ is the coefficient determining the correlation ratio and the reliability of the model.

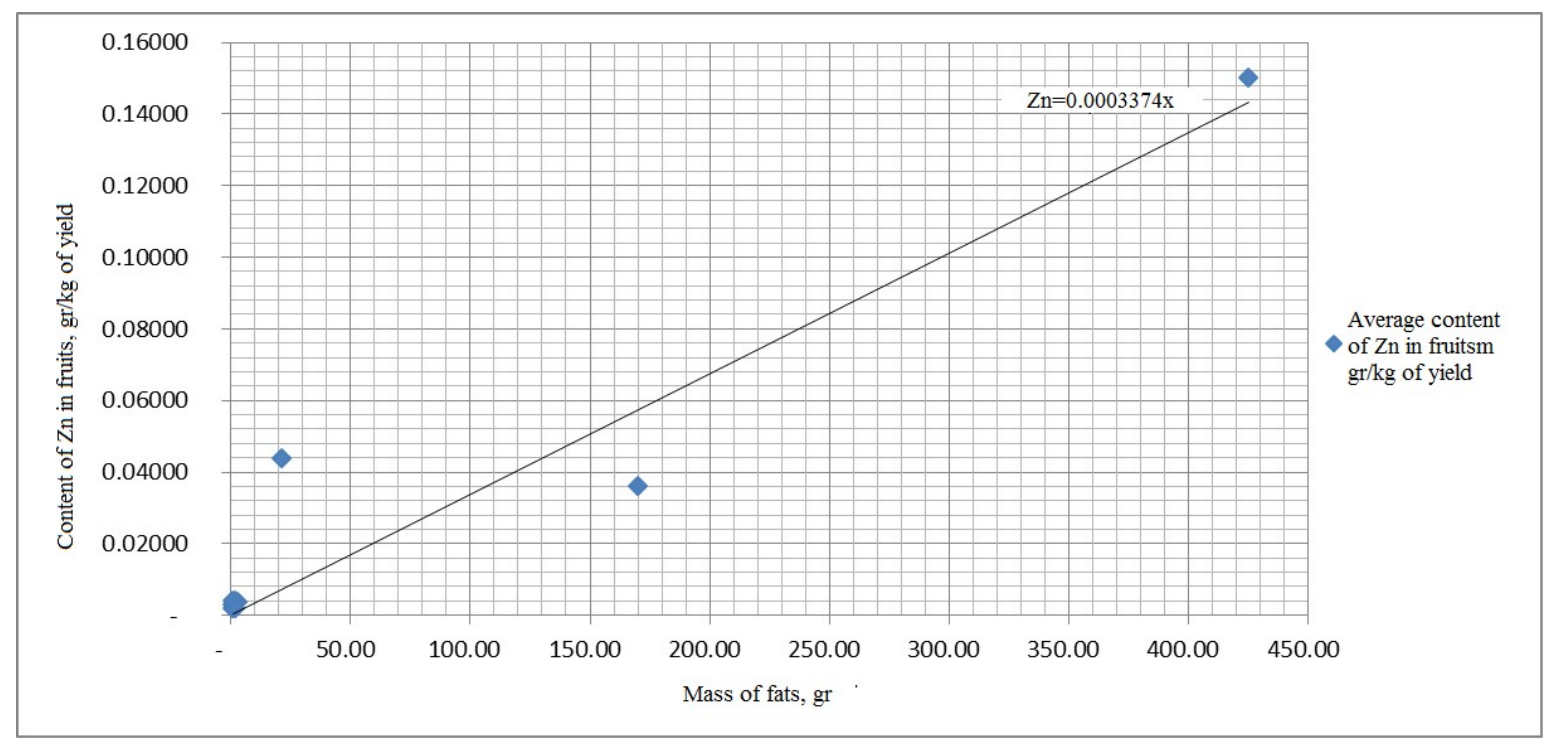

Fig.11. Dependence of zinc ( $\mathrm{Zn}$ ) content in fruits on fat weight. $\mathrm{R}=0.955$, where $\mathrm{R}$ is the coefficient determining the correlation ratio and the reliability of the model. 


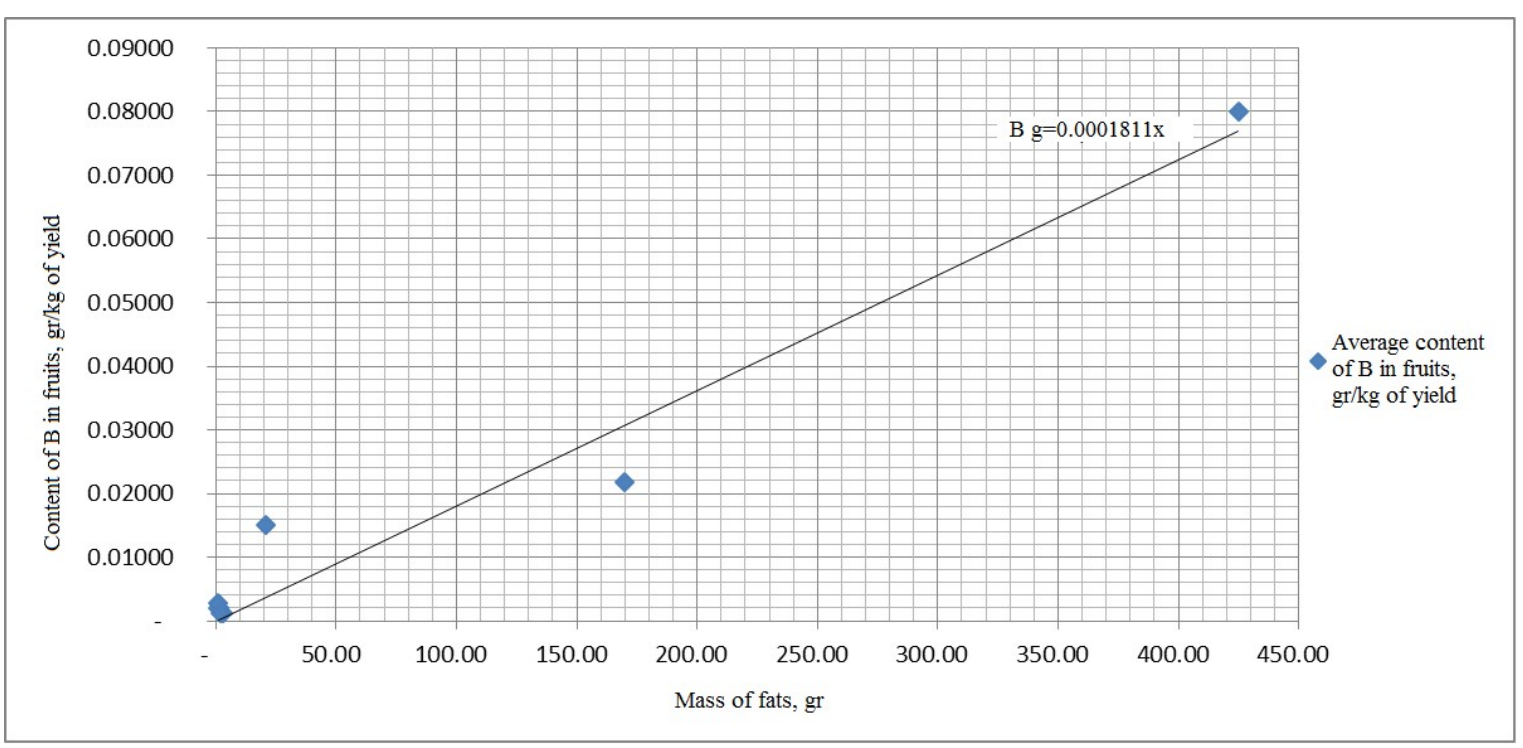

Fig.12. Dependence of boracium (B) content in fruits on fat weight. $R=0.981$, where $R$ is the coefficient determining the correlation ratio and the reliability of the model.

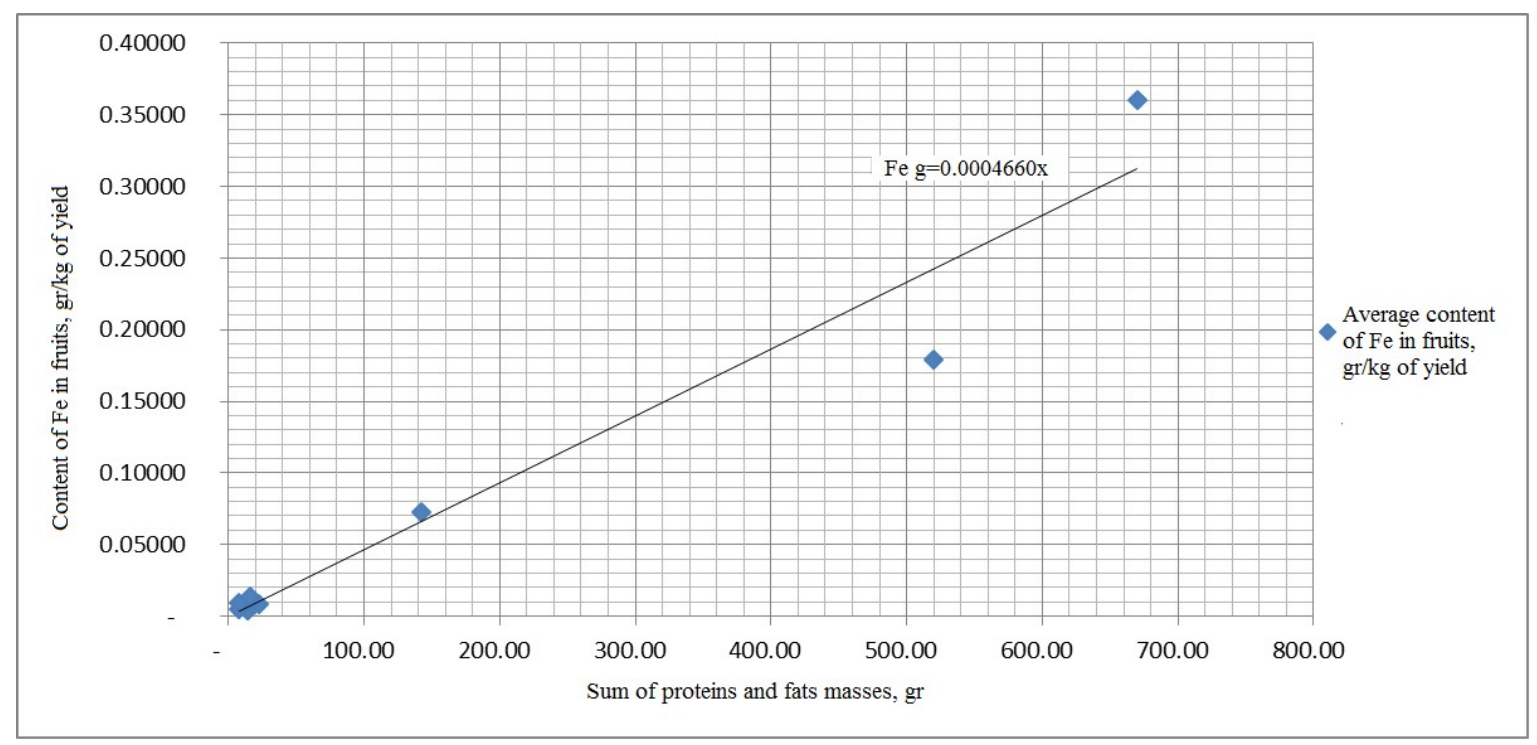

Fig.13. Dependence of ferrum $(\mathrm{Fe})$ content in fruits on the sum of protein and fat weight. $\mathrm{R}=$ 0.974 , where $\mathrm{R}$ is the coefficient determining the correlation ratio and the reliability of the model. 


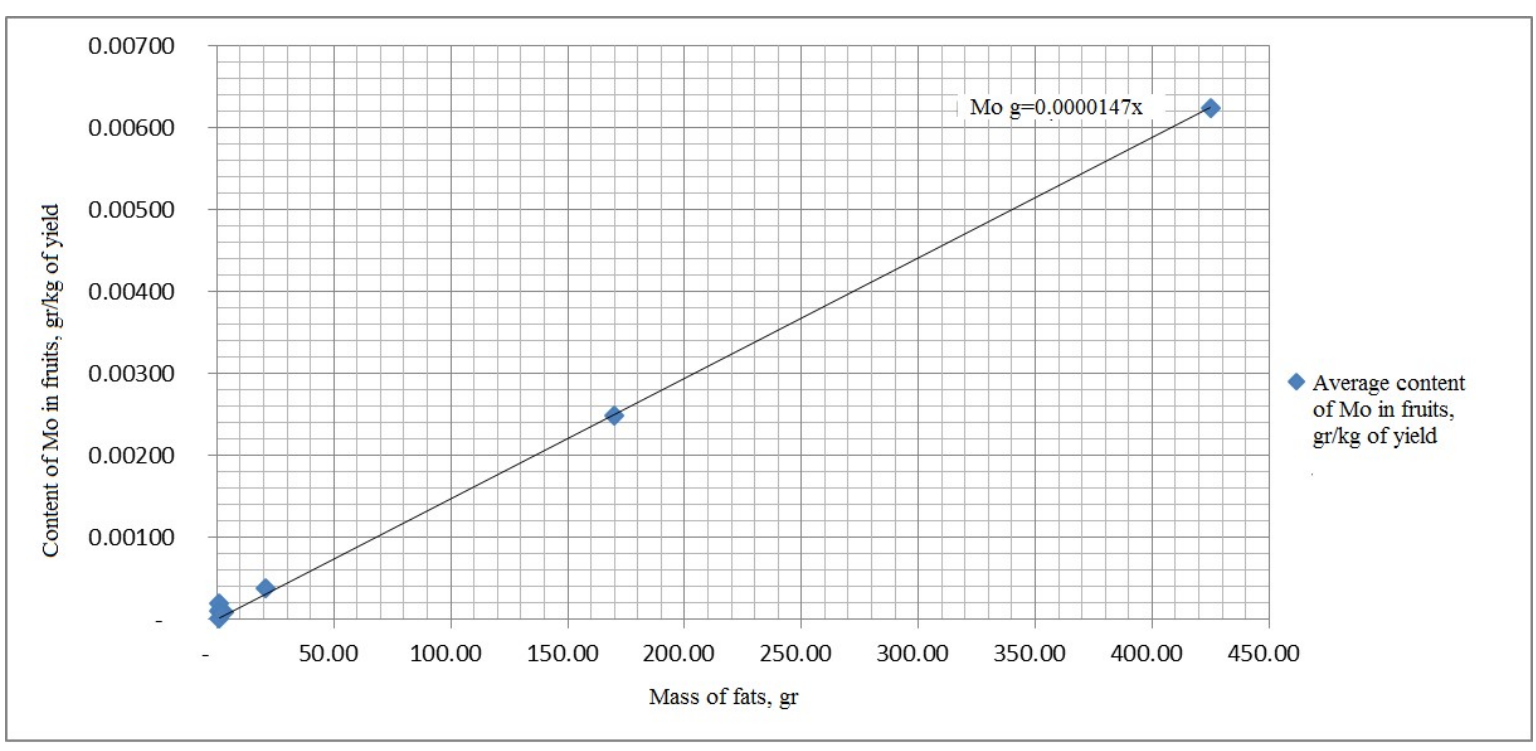

Fig.14. Dependence of molybdenum (Mo) content in fruits on fat weight. $R=1$, where $R$ is the coefficient determining the correlation ratio and the reliability of the model.

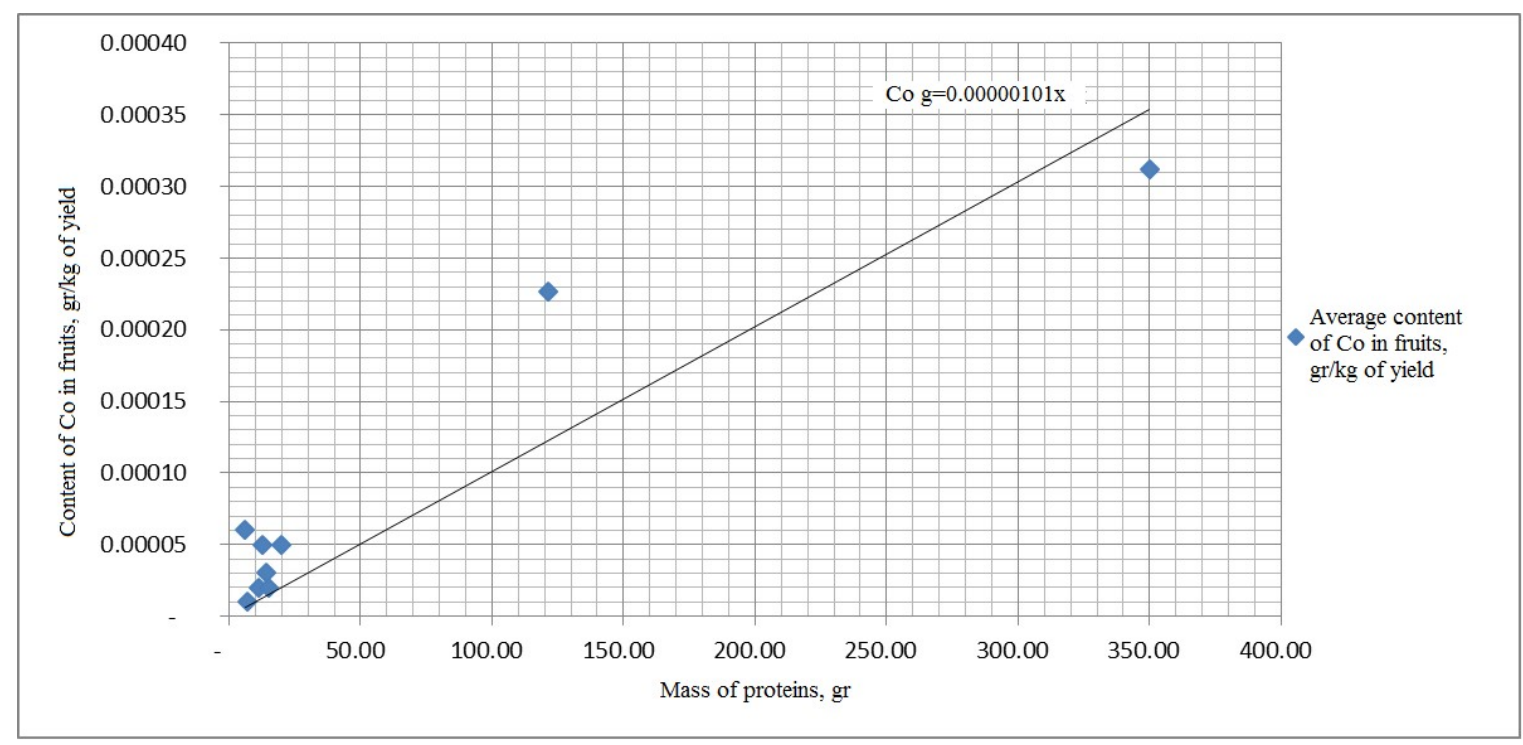

Fig.15. Dependence of cobalt $(\mathrm{Co})$ content in fruits on protein weight. $\mathrm{R}=0.937$, where $\mathrm{R}$ is the coefficient determining the correlation ratio and the reliability of the model.

How to cite this article:

Reichardt A V, Lebedev S V. Conservation law of plants' energy value dependence of plants' need in nutrients on biochemical composition. J. Fundam. Appl. Sci., 2017, 9(2S), 1329-1369. 